Classification

Physics Abstracts

$81-07.85-61.16 \mathrm{D}$

\title{
Quantitative Analysis of Nicalon Fibres in TEM by EDXS and EELS
}

\author{
Dominique Imhoff, Nathalie Mozdzierz and Monika Backhaus-Ricoult
}

Laboratoire de Physique des Matériaux, CNRS, 1 Place A. Briand, 92195 Meudon, France

(Received December 1, 1994; accepted March 24, 1955)

\begin{abstract}
Résumé. - La composition chimique de fibres Nicalon dans des composites SiC-C-SiC bruts de fabrication et recuits est étudié en Microscopie Electronique en Transmission. Les modes analytiques EDX et EELS, complétés par l'imagerie haute résolution et la diffraction électronique sont utilisés pour caractériser les fibres constituées de nanophases contenant du carbone, de l'oxygène et du silicium. Une attention particulière est portée sur l'analyse quantitative du carbone et de l'oxygène pour laquelle différentes méthodes de traitement sont évaluées et comparées. Les limites des techniques employées sont discutées. Le coeur de la fibre et sa périphérie dans le matériau brut de fabrication sont composées respectivement de $57.5 \%$ de silicium (38.6\%at), $29 \%$ de carbone (45.5\%at), $13.5 \%$ d'oxygène (15.9\%at) et de $53 \%$ de silicium (34.4\%at), $32 \%$ de carbone (48.5\%at) et de $15 \%$ d'oxygène en concentration massique relative $(17.1 \%$ at). La concentration relative d'oxygène dans la fibre évolue pendant les recuits sous différentes pressions partielles d'oxygène. La fibre est constituée de nanocristaux de $\mathrm{SiC}$, de carbone turbostratique et d'une phase oxycarbure amorphe.
\end{abstract}

\begin{abstract}
The global and local chemical composition of Nicalon fibres present in as- fabricated and annealed $\mathrm{SiC}-\mathrm{C}-\mathrm{SiC}$ composites are analysed by Analytical Transmission Electron Microscopy. EDXS, EELS, HREM and electron diffraction are used to characterise the fibre, which consists of different nanophases containing carbon, oxygen and silicon. Special attention is paid to the quantitative analysis of carbon and oxygen; different data treatment in EDXS and EELS are evaluated and compared. The limitations of the analysis techniques are discussed. The global composition of the core and the periphery of the fibre in the as-fabricated composite is determined to be: $57.5 \mathrm{wt} \%$ $\mathrm{Si}, 29 \mathrm{wt} \% \mathrm{C}, 13.5 \mathrm{wt} \% \mathrm{O}$ (38.6at\% Si, $45.5 \mathrm{at} \% \mathrm{C}, 15.9 \mathrm{at} \% \mathrm{O})$ and $53 \mathrm{wt} \% \mathrm{Si}, 32 \mathrm{wt} \% \mathrm{C}, 15 \mathrm{wt} \%$ $\mathrm{O}(34.4 \mathrm{at} \% \mathrm{Si}, 48.5 \mathrm{at} \% \mathrm{C}, 17.1 \mathrm{at} \% \mathrm{C})$, respectively. After annealing in atmospheres with different oxygen partial pressures, the global oxygen content in the (fibre changes. The fibre constituents are silicon carbide nanocrystals, graphite units and an amorphous silicon oxycarbide phase.
\end{abstract}

\section{Introduction}

Nicalon fibres and their chemical and structural evolution have been a significant research topic over the last decade. Nicalon fibres constitute one of the main types of continuous silicon carbide based fibres that are used to reinforce many ceramic and polymer composites. They are obtained by pyrolysis of a polysilane precursor [1]. During the final heat treatment at approximately $1573 \mathrm{~K}$, 
the polysilane decomposes under formation of $\mathrm{Si}-\mathrm{C}$ and $\mathrm{C}-\mathrm{C}$ bonds, yielding a three-phase mixture of silicon carbide, carbon and silicon oxycarbide [2]. The relative amount, the exact composition, and the distribution of these phases is determined by the oxygen content initially present in the precursor fibre, by the conditions of pyrolysis (temperature, time, atmosphere), and by any additional heat treatment [3-5].

In the past, the chemical composition of the NLM202 fibre (grade NG200) was determined by various techniques (see Tab. I), yielding scattered data [6-14]. This lack of coherence among reported data may be ascribed to the accuracy of the different techniques used, to compositional variations between the outer and inner regions of the fibres, and to compositional fluctuations during processing.

Some microstructural features of the fibre were determined by Transmission Electron Microscopy (TEM), X-ray diffraction and X-ray Photoelectron Spectroscopy (XPS). After processing, the fibre was composed of small silicon carbide crystals ranging in size from 1 to $3 \mathrm{~nm}$ and of graphite crystals of $1 \mathrm{~nm}$ in diameter (turbostratic carbon) [15-17]. These crystals were embedded within a silicon oxycarbide amorphous phase, as determined by XPS, Electron Spectroscopy for Chemical Analysis (ESCA) and Extended X-Ray Absorption Fine Structure (EXAFS) [12, 18, 19]. The chemical composition of the fibre, however, was not precisely identified (see Tab. II). Theoretical models for the structure of the Nicalon fibre were developed. Laffon et al. [19] proposed a dense network of silicon tetrahedra with $\mathrm{Si}-\mathrm{O}$ and $\mathrm{Si}-\mathrm{C}$ bonds for the oxycarbide $\left(\mathrm{SiO}_{x} \mathrm{C}_{y}\right.$, $x+y=4)$, containing small embedded graphite units. A different approach to the structure and composition of the oxycarbide was taken by Schreck et al. [12], who considered ionic bonding and obtained from the electroneutrality condition $x+2 y=2$.

Table I. - Chemical composition of NLM202 fibre (grade NG200) obtained by various techniques.

\begin{tabular}{|l|l|l|l|l|}
\hline $\mathrm{Si}$ & $\mathrm{C}$ & 0 & Technique & Ref \\
\hline 54.3 & 30 & 11.8 & & {$[6]$} \\
\hline 52.2 & 35.8 & 11.8 & EELS; SIMS & {$[7]$} \\
\hline 56.5 & 32.8 & 10.7 & & {$[8]$} \\
\hline 57.3 & 30 & 12.7 & EPMA & {$[9]$} \\
\hline 54.2 & 29.8 & 13 & ESCA & {$[10]$} \\
\hline 51.5 & 30.5 & 18 & AES & {$[11]$} \\
\hline 52.2 & 35.8 & 12 & XPS; ESCA & {$[12]$} \\
\hline 57.9 & 28.4 & 13.2 & TEM/EDXS & {$[13]$} \\
\hline 56 & 31 & 13 & XPS & {$[18]$} \\
\hline 57 & 29 & 14 & SEM/EDXS & {$[14]$} \\
\hline & \multicolumn{5}{|c}{ (composition in weight \%) }
\end{tabular}

In summary we concluded that, despite multiple efforts, the detailed structure and chemical composition of as-fabricated Nicalon fibre is not yet completely understood. Results for heattreated fibres showed even greater dispersion, undoubtedly due to the evolution of the microstucture of the Nicalon fibre during the high-temperature annealing. At such temperatures, sluggish kinetics are overcome and the metastable material approaches thermodynamic equilibrium: 
the silicon oxycarbide phase decomposes and the crystalline phases of the fibre undergo Ostwald ripening. The decomposition products of the fibre depend on the type of the surrounding atmosphere and especially on silicon monoxide and carbon monoxide partial pressures [21-27]. Both, active and passive oxidation were observed, depending on the oxygen partial pressure and temperature [27].

Table II. - Composition found for the oxycarbide $\mathrm{SiO}_{x} C_{y}$.

\begin{tabular}{|l|l|l|l|l|}
\hline$\% \mathrm{SiC}$ & $\% \mathrm{SiO}_{\mathrm{x}} \mathrm{C}_{\mathrm{y}}$ & $\% \mathrm{C}$ & $\begin{array}{l}\text { oxycarbide } \\
\text { stochiometry }\end{array}$ & ref \\
\hline $55 \mathrm{wt} \%$ & $40 \mathrm{wt} \%$ & $5 \mathrm{wt} \%$ & $\mathrm{SiO}_{1.15} \mathrm{C}_{0.85}$ & {$[11]$} \\
\hline $57 \mathrm{wt} \%$ & $31 \mathrm{wt} \%$ & $12 \mathrm{wt} \%$ & $\mathrm{SiO}_{1.1} \mathrm{C}_{0.45}$ & {$[10]$} \\
\hline $46 \mathrm{vol} \%$ & $34 \mathrm{vol} \%$ & $20 \mathrm{vol} \%$ & - & {$[18]$} \\
\hline 44 to 50 & $\begin{array}{l}22 \text { to } \\
\text { vol\% }\end{array}$ & $\begin{array}{l}25 \text { to } \\
\text { vol\% }\end{array}$ & - & {$[20]$} \\
\hline 53 vol\% & $23 \mathrm{vol} \%$ & 24 vol\% & $\mathrm{SiO}_{1.09} \mathrm{C}_{0.45}$ & {$[12]$} \\
\hline
\end{tabular}

In addition to the above considerations, the microstructural evolution of the fibre in a composite depends on the matrix, since the chemical potentials of its constituents are imposed at the fibre surface and may thereby induce different chemical reactions. As an example, the reader is referred to the $2 \mathrm{D}$ Nicalon fibre-C(interphase)-SiC matrix composite described by the authors [14].

In the present work, analytical transmission electron microscopy combined with energy dispersive X-ray spectroscopy (EDXS) and electron energy loss spectroscopy (EELS) is used to determine the global and local structures of the fibre and its constituents as well as their chemical composition. These localized characterization techniques are well adapted to the complexity of the material and to the small scale (nanometer dimensions) of its constituent phases. The quantitative analysis of oxygen and carbon by TEM/EDX is generally fraught with many difficulties. Problems which must be overcome include X-ray absorption by the sample and the detection system, low values of fluorescence yield, limited energy resolution of the detector, substraction of the background signal present under each characteristic peak, and contamination under the electron beam. Some of these problems are also encountered for quantification of the EELS data. In addition, multiple scattering and the presence of fine structure on the edges perturb the quantification.

In order to quantify the fibre composition with best precision, EDX and EEL spectra are simultaneously acquired and treated by different techniques. The linear interpolation and MLS (Multiple Least Square fit) for suppressing the EDX background signal (2.3.1) are compared. Two methods are used to correct the absorption effect in EDXS: the first, known as the Van Cappellen method [29], does not require thickness measurements, while the second uses the Philibert-Tixier model [30] and sample thickness is estimated from the low loss region of EELS (2.3.2). Elemental quantification of EELS is obtained either by a hydrogenic model (SIGMAK(L)) or by experimental $\mathrm{k}$ factors using standard specimens (2.4). Plural scattering is taken into account by studying 
the EELS signal evolution with sample thickness. All methods and their consequent results are described separately and then compared and discussed in section 3.

\section{Experimental Procedures}

2.1 Material Preparation. - The SiC (Nicalon fibre)-C-SiC composite was furnished by SEP (details on its fabrication are given in [25]). It was annealed at different temperatures in oxidizing and neutral atmospheres. Results are shown here for the as-fabricated material and for samples annealed at $1673 \mathrm{~K}$ for $25 \mathrm{~h}$ in either a neutral atmosphere (oxygen partial pressure $p_{\mathrm{O} 2}=10^{-6} \mathrm{~atm}$ and silica activity $\left.a_{\mathrm{SiO} 2}=1\right)$ or an oxidizing atmosphere $\left(p_{\mathrm{O} 2}=0.21 \mathrm{~atm}\right.$, $\left.a_{\mathrm{SiO} 2}=1\right)$. TEM samples were prepared from these specimens by mechanically polishing down to $80 \mu \mathrm{m}$ and then ion milling in a cold stage at approximately $100 \mathrm{~K}$, using $4-5 \mathrm{kV}$ and $0.5 \mathrm{~mA}$ beam relatively tilted by $15^{\circ}$ over the sample surface. Only fibre cross- sections were used for observations and analysis.

Thin foils of polycrystalline silica and pure polycrystalline SiC were prepared as reference standards for the quantitative analysis of oxygen and carbon by EDXS and PEELS. This silicon carbide was fabricated from pure powders by Hot Isostatic Pressing (HIP) [28] and was considered to be the best reference material. Silica, silicon carbide, silicon, amorphous carbon and graphitic carbon were used as references for the near edge fine structures of the EELS spectra.

2.2 SAMPLE OBSERVATIONS. - The following transmission electron microscopes (200 $\mathrm{KeV}$, $\mathrm{LaB}_{6}$ gun) were used: a TOPCON $002 \mathrm{~B}$, with a $1.8 \mathrm{~nm}$ point to point resolution, was used for high resolution imaging of the fibre, and a JEOL 2000FX, equipped with a LINK Si:Li EDX detector and a GATAN 666 Parallel EELS spectrometer was used for chemical analysis. Both microscope vacuums were maintained under $10^{-5} \mathrm{~Pa}$.

Selected area electron diffraction, with an aperture of $10 \mu \mathrm{m}$, was conducted on different regions of the fibre and on differently treated fibres. From these diffraction patterns, the contribution of the different phases to the material and the average size of the crystallites could be estimated.

Carbon and silicon carbide lattice fringes were obtained by imaging with a $120 \mu \mathrm{m}$ aperture. The basal planes of carbon and the (111), (110) planes of silicon carbide could be imaged for those crystals adequately oriented with respect to the electron beam.

Different probe sizes of 6,20,40,100,700 nm were used: larger probe sizes for global analysis (and comparison to SEM/EDXS and EPMA results of homogeneous zones) and nanometer probe sizes for studying the local evolution of phases present in a fibre. The take-off angle in EDXS was $70^{\circ}$ and the specimen was untilted. Acquisition time was between $100 \mathrm{~s}$ and $300 \mathrm{~s}$. Energy loss spectra were obtained in diffraction mode for acquisition times of $2 \mathrm{~s}$ to $100 \mathrm{~s}$. The collection angles were $10 \mathrm{mrad}$ for a camera length of $10 \mathrm{~cm}$.

The specimen holder had to be cooled to $100 \mathrm{~K}$ by liquid nitrogen in order to avoid sample contamination. It was impossible to precisely determine the carbon concentrations without this cooling equipment. The beam current densities had to be kept below $4 \mathrm{pA} \cdot \mathrm{nm}^{-2}$. Under these conditions, the carbon signal was stable over acquisition times up to $500 \mathrm{~s}$. At the beginning and end of each EDX acquisition an EELS spectrum was acquired. From its low loss region the actual sample thickness was determined. Thickness changes could then be interpreted as a contamination layer.

2.3 EDX SPECTRA QUANTIFICATION. - Quantitative analysis of the fibre was made difficult by the presence of very light elements, particularly carbon. In order to determine the best operating 
conditions, several methods were used. First, we compared the linear interpolation and Multiple Least Square fitting (MLS) methods to extract the background signal (Bremsstrahlung). Second, different absorption corrections were applied by invoking a) the "Van Cappellen" -method [29], which avoids specimen thickness measurements, and b) the "Tixier-Philibert"-model [30] using thickness estimates from electron energy loss spectra. In both cases, according to the CliffLorimer expression [31], a proportionality factor, $k$, between weight concentration ratio and peak intensity ratio is introduced. The carbon and oxygen $k$ factors relatively to silicon were determined for the $\mathrm{SiC}$ and $\mathrm{SiO}_{2}$ reference standards and applied to the corresponding phases in the composite. The carbon $k$-factor was verified during each session to take account for any evolution in the detector response.

2.3.1 Extraction of Background Signal. - Due to small thickness of TEM specimens (5 nm $-300 \mathrm{~nm}$ ) and the relatively high energy of the incident electrons, the Bremsstrahlung intensity remains low compared to that of the characteristic peaks. Since the EDX detector sensibility decreases with contamination, it was conditionned before each TEM session in order to clean its surface from any water contamination: $68 \mathrm{eV} \mathrm{FWHM}$ were obtained for the carbon peak.

We used and compared two methods for background subtraction: linear interpolation and MLS method. Linear interpolation is applied in an energy interval of $120 \mathrm{eV}$ for the carbon peak and $140 \mathrm{eV}$ for the oxygen and silicon peaks. In the MLS method, spectra are digitally filtered, before suppressing the slowly varying spectrum background. Filtered profiles of the unknown specimen are then fitted to the filtered profiles of the standards. The peak area and the statistical error were calculated for each element.

2.3.2 Absorption Correction. - In order to quantify the carbon concentration, it is critical to correct for absorption effects, even when the materials are composed of light elements (3.2.3).

Van Cappellen developed a method to quantify the EDX spectra of thin foils which takes absorption and fluorescence effects into account without direct determination of sample thickness. In this method, multiple spectra are acquired for various unknown sample thicknesses. The intensity ratio of two characteristic peaks, for example $\mathrm{C}_{\mathrm{K}} / \mathrm{Si}_{\mathrm{K}}$, are then plotted as a function of a reference element intensity, here Si. Silicon intensity is proportional to sample thickness when other parameters such as beam current and composition homogeneity remain fixed. Extrapolation of these curves back to zero thickness and introduction of Cliff Lorimer expressions allowed us to obtain $k$-factors for each element. Following normalization of the total concentration to $100 \%$, relative elemental compositions were obtained.

The Van Cappellen method could not be applied to inhomogenous regions of the fibre or next to the interphase. In these cases, the simultaneous acquisition of electron energy low loss spectra allowed us to determine the local specimen thickness, relative to the mean free path, $\lambda$. The estimated thickness value is then introduced into the correction formula of the Tixier-Philibert model [30] or used for the localisation on the Van Cappellen curves of the standards. Zero loss peak intensity, $I_{0}$, and total spectrum intensity, $I_{\mathrm{T}}$ (up to the maximum energy loss collected), provide a relative measure of $t / \lambda$, according to the expression,

$$
t / \lambda=-\log \left(I_{0} / I_{\mathrm{T}}\right)[32]
$$

The mean free path $\lambda$ for inelastically scattered electrons can either be obtained by a theoretical expression:

$$
\lambda=\frac{2 a_{0} m_{0} v^{2}}{E_{\mathrm{p}} \ln \left(1+\beta / \theta_{\mathrm{E}}\right)}[32]
$$

where $a_{0}, m_{0}, v, E_{\mathrm{p}}$ and $\theta_{\mathrm{E}}$ are respectively the Bohr radius, the electron weight at $v=0$, the velocity of incident electrons, the plasmon energy and the characteristic scattering angle. In this 
expression and for fixed geometry the mean freee path depends essentially on the value of the plasmon energy and the values of a free electron in $\mathrm{SiC}$ and $\mathrm{SiO}_{2}$ are $120 \mathrm{~nm}$ and $116 \mathrm{~nm}$, respectively, at $200 \mathrm{kV}$. $\lambda$ can be obtained by experimental measurements. Calibration on an evaporated thin layer $(70 \mathrm{~nm})$ of $\mathrm{SiC}$ [33] produced a $15 \%$ difference compared to the calculated value.

From the absorption factors in the Si-O-C system, fluorescence corrections are not needed. However, they would be automatically included in the Van Cappellen approach.

2.4 ElEMENTAL COMPOSITION DETERMined by EELS SPECTRA. - Two approaches were used to quantify the EELS spectra, based either on cross-sectional calculations (SIGMAK(L)) [32] or on experimentally determined $k$ factors.

The $\mathrm{Si}_{\mathrm{K}}$ edge $(1839 \mathrm{eV})$ was not used for quantification, since its signal intensity was much smaller than that of the $\mathrm{Si}_{\mathrm{L}}(99-105 \mathrm{eV})$ edge. Quantification on a single spectrum and a reasonable energy dispersion $(1 \mathrm{eV} / \mathrm{ch})$ was accomplished by using $\mathrm{Si}_{\mathrm{L}}(99-105 \mathrm{eV}), \mathrm{C}_{\mathrm{K}}(284 \mathrm{eV})$ and $\mathrm{O}_{\mathrm{K}}(532 \mathrm{eV})$ edges.

The SIGMAK(L) method is based on the hydrogenic model of Egerton [32]. Due to the complexity of cross-sectional calculations (i.e. simulated EELS edges), simplified models have been developed in the past. Their limitations, however, become apparent when important near edge fine structures are present or when multiple scattering occurs. They were particularly important for the $\mathrm{Si}_{\mathrm{L}}$ edge of $\mathrm{SiC}, \mathrm{SiO}_{2}$ and $\mathrm{SiO}_{x} \mathrm{C}_{y}$. The influence of the fine structure was shown by varying the position and width of the energy interval of the core-edges for the $\mathrm{SiC}$ and $\mathrm{SiO}_{2}$ standards.

In the second method, $k$ factors are determined by using well defined stoichiometric standards:

$$
\frac{C_{\mathrm{A}}}{C_{\mathrm{B}}}=\frac{S_{X}^{\mathrm{A}}(\beta, \Delta E)}{S_{X}^{\mathrm{B}}(\beta, \Delta E)} \cdot \frac{\sigma_{X}^{\mathrm{B}}(\beta, \Delta E)}{\sigma_{X}^{\mathrm{A}}(\beta, \Delta E)}=k_{\mathrm{AB}} \cdot \frac{S_{X}^{\mathrm{A}}(\beta, \Delta E)}{S_{X}^{\mathrm{B}}(\beta, \Delta E)}
$$

with $C_{\mathrm{A}}, C_{\mathrm{B}}$ being the elemental concentrations, $S_{X}^{\mathrm{A}}, S_{X}^{\mathrm{B}}$ the characteristic inner shell areas of A and $\mathrm{B}, \sigma_{X}^{\mathrm{A}}, \sigma_{X}^{\mathrm{B}}$ the partial cross sections, $\beta$ the collection angle and $\Delta E$ the chosen energy interval [32]. Even though the equation formally is similar to the Cliff-Lorimer expression in the EDXS approach, the EELS $k$ factors depend on both, the collection angle $\beta$ of the spectrometer and the characteristics of the chosen energy intervals $\Delta E$. The collection angle itself is a function of the convergence angle, the angular distribution of transmitted electrons and the beam geometry between the objective lens and the PEELS spectrometer (i.e. camera length, spectrometer entrance aperture). The effect of multiple scattering on the quantification is experimentally corrected in the present work by using thickness dependant $k$ factors.

The chemical shift and near edge fine structure of the edges were studied for different fibre regions and differently treated composites. In the case of silicon, the energy threshold depended on its chemical environment and changed for different compounds: a chemical shift of $6 \mathrm{eV}$ for the $\mathrm{Si}_{\mathrm{L}}$ edge threshold was observed between $\mathrm{SiO}_{2}(105 \mathrm{eV})$ and $\mathrm{SiC}(99 \mathrm{eV})$. No chemical shift (within experimental resolution) was measured for carbon or oxygen. Fibre spectra were compared to standards or mixtures of different standards. The important differences in the fine structure and the different chemical shift for different phases of the fibre show why the hydrogenic model fails for the EELS quantification and underline the need of quantification with standards.

\section{Results and Discussion}

In this section, the results for the different fibre materials are given and the experimental methods are discussed in terms of their precision and reliability. 
3.1 FIBRE STRUCTURE. - The Nicalon fibres in the as-fabricated composite are separated from the silicon carbide CVI matrix by a thin carbon interphase. A typical fibre cross-section is shown in Figure 1.

a)

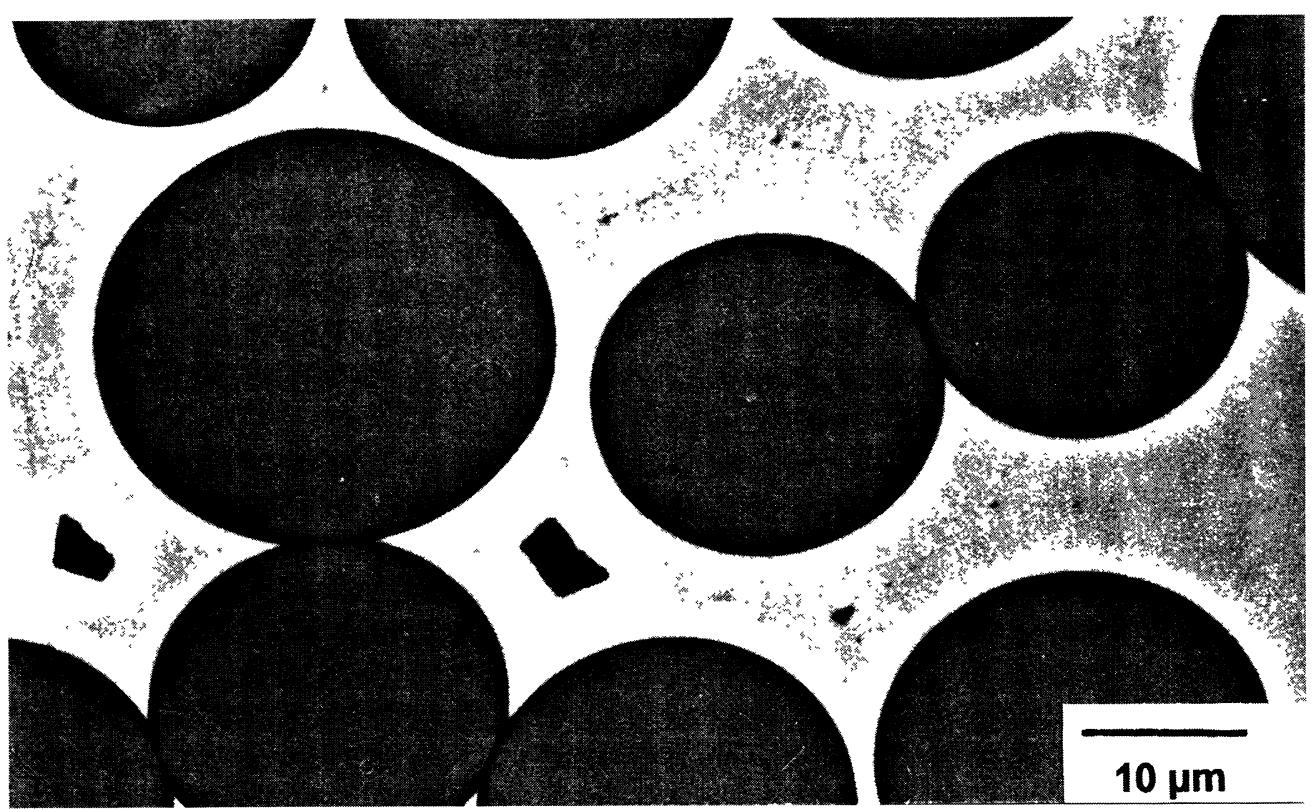

b)

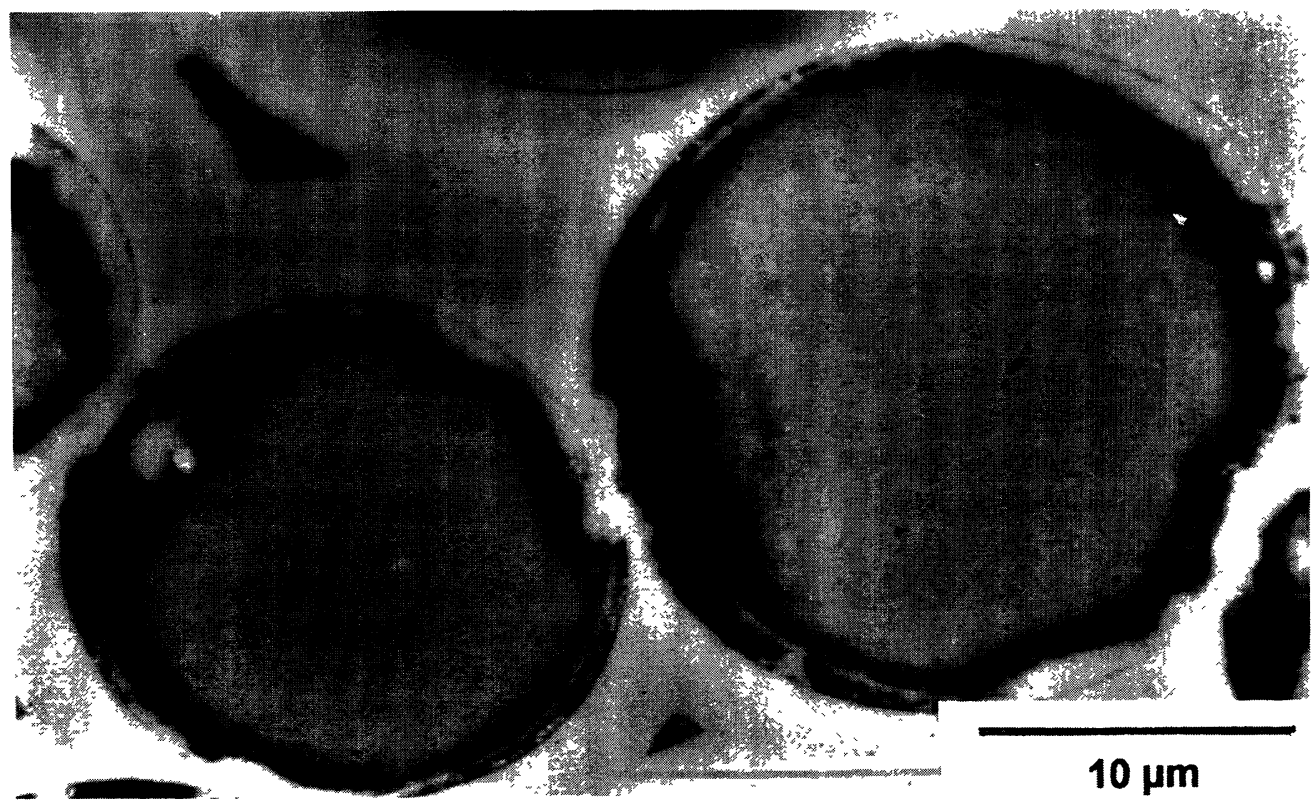

Fig. 1. - SEM image of typical fibre cross section in the a) as-fabricated and b) annealed composites. 
3.1.1 As-Fabricated Composite (Fig. 2). - Electron diffraction of the fibre in the as-fabricated composite yielded a number of diffuse rings, identified as belonging to silicon carbide and carbon (Fig. 2b). From the width and separation of the silicon carbide rings, it was concluded that the average crystal size in the material was approximately $2-3 \mathrm{~nm}$. This was confirmed by high resolution imaging of the fibre, Figure $2 b$, which revealed $2-3 \mathrm{~nm}$ size silicon carbide particles with an interplanar distance of $0.25 \mathrm{~nm}$ and about $1 \mathrm{~nm}$ size carbon particles with an interplanar spacing of $0.35 \mathrm{~nm}$. Carbon and silicon carbide crystallites were uniformly distributed throughout the material. From their frequency in the image and their limited visibility due to misorientation relative to the electron beam axis $\left( \pm 5^{\circ}[14]\right)$, a total content of $50-60$ vol\% SiC and $20-30$ vol\% turbostratic carbon was estimated. The frequence of silicon carbide crystals and turbostratic carbon crystals was lower close to the outer periphery of the fibre than in the core.

3.1.2 Composite Annealed at $1673 \mathrm{~K}$ in Neutral or Oxidising Atmosphere (Fig. 3). - The diffraction pattern of the annealed fibre was less diffuse and the rings were spotty and discontinuous (Fig. 3b), indicating growth of the silicon carbide crystallites to sizes above $20 \mathrm{~nm}$. The following phases were identified: silicon carbide, graphitic carbon and silicon oxycarbide.

High resolution imaging of the fibre (Fig. $3 b$ ) revealed that the fibre structure had undergone a significant evolution during the annealing in neutral atmosphere: large silicon carbide crystals of approximatly $50 \mathrm{~nm}$ have formed. These crystals have well defined facets, and stacking faults are occasionally present. Multiple crystals are often grown together. The crystals are generally surrounded by a thin amorphous film. The carbon crystals did not increase in size and are less frequent than in the original material.

Crystal growth in the fibre was more limited in an oxidising atmosphere, but all three phases could still be distinguished (details in [14]).

\subsection{EDXS RESULTS FOR THE FIBRE}

3.2.1 Comparison Between Linear Interpolation and MLS Methods. - Figure 4 shows a typical example of an EDX spectrum of the fibre core region from the as-fabricated composite (acquisition time $200 \mathrm{~s}$, probe size $40 \mathrm{~nm}$ and sample thickness $50 \mathrm{~nm}$ ). Prior to filtering, the triggered noise peak at zero energy was suppressed for a better fit and a constant is added instead between $0 \mathrm{eV}$ and point A (Fig. 4). Energy resolution was sufficient to separate "zero peak", carbon, and oxygen. The background to signal ratios (ratio between maximum values) were 0.035 and 0.022 for carbon and oxygen peaks, respectively.

Figure 5 presents the apparent weight concentrations of $\mathrm{C}, \mathrm{O}$ and $\mathrm{Si}$ in the fibre core of the asfabricated composite, calculated by both, the linear interpolation and MLS method for a series of points obtained for increasing thickness. The $k$ factors cannot be compared because the integration interval energy was not the same for the linear interpolation and MLS fit. Since the fibre core was homogeneous, absorption is corrected in both cases by the Van Cappellen method. Linear interpolation and MLS method give similar results. Dispersion in the results is less than 5\% up to approximately $300 \mathrm{~nm}$ sample thickness (point 5) for all elements, including carbon. Divergence of the two methods becomes apparent with increasing sample thickness. This can be attributed to absorption of the carbon and oxygen peaks. However, even at large thicknesses $(700 \mathrm{~nm})$, the difference between the two methods remains always less than $10 \%$ for carbon (point 10).

In general, the MLS method can better handle peak overlap (i.e., the presence of nitrogen or boron in the fibre) and shows in such case some advantages when compared to the simple linear interpolation. Slight differences in the carbon quantification were observed which were attributed to small background changes at the foot of the "zero peak" and relied to the different states of the detector surface. Consequently, the MLS method was used for all subsequent results. 
a)

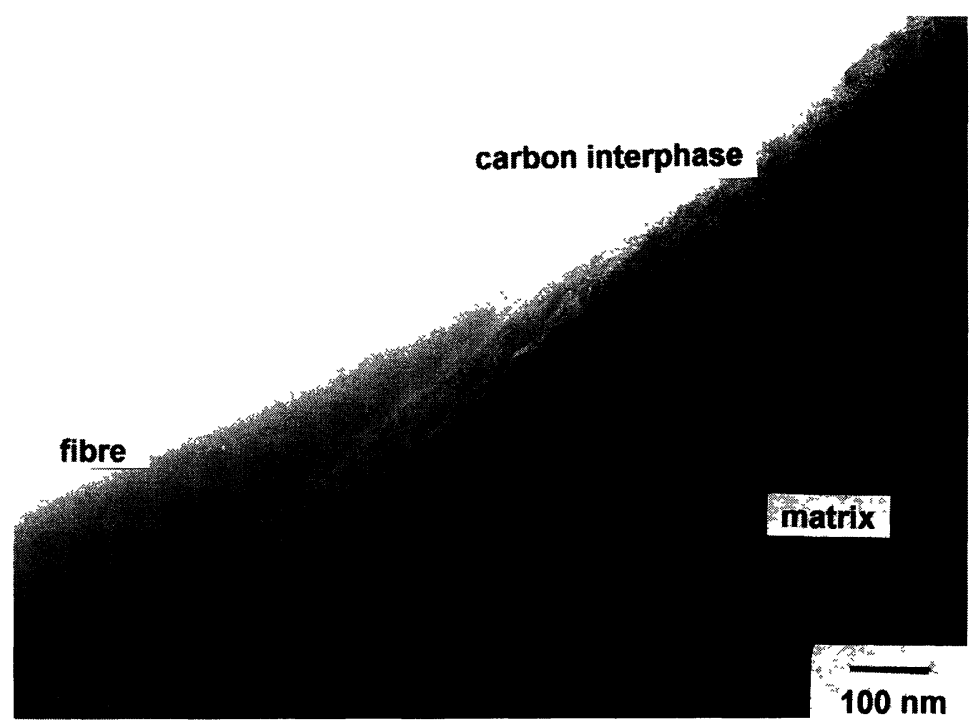

b)

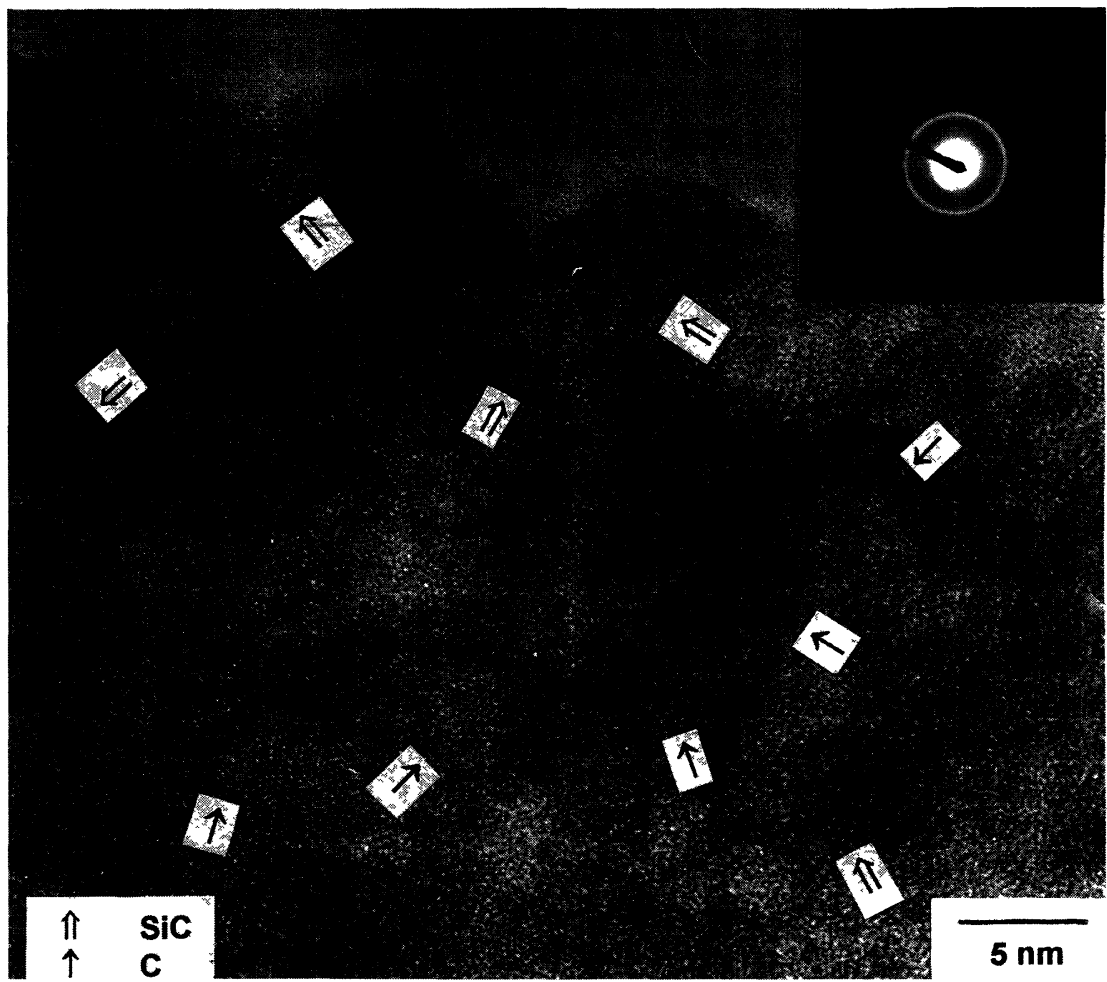

Fig. 2. - a) TEM bright field image and b) HREM image with corresponding diffraction pattern in the Nicalon fibre of the as-fabricated composite. bon/silicon and oxygen/silicon EDX peak intensity ratios for $\mathrm{SiC}$ (HIP), $\mathrm{SiC}$ matrix, $\mathrm{SiO}_{2}$, and the 
a)

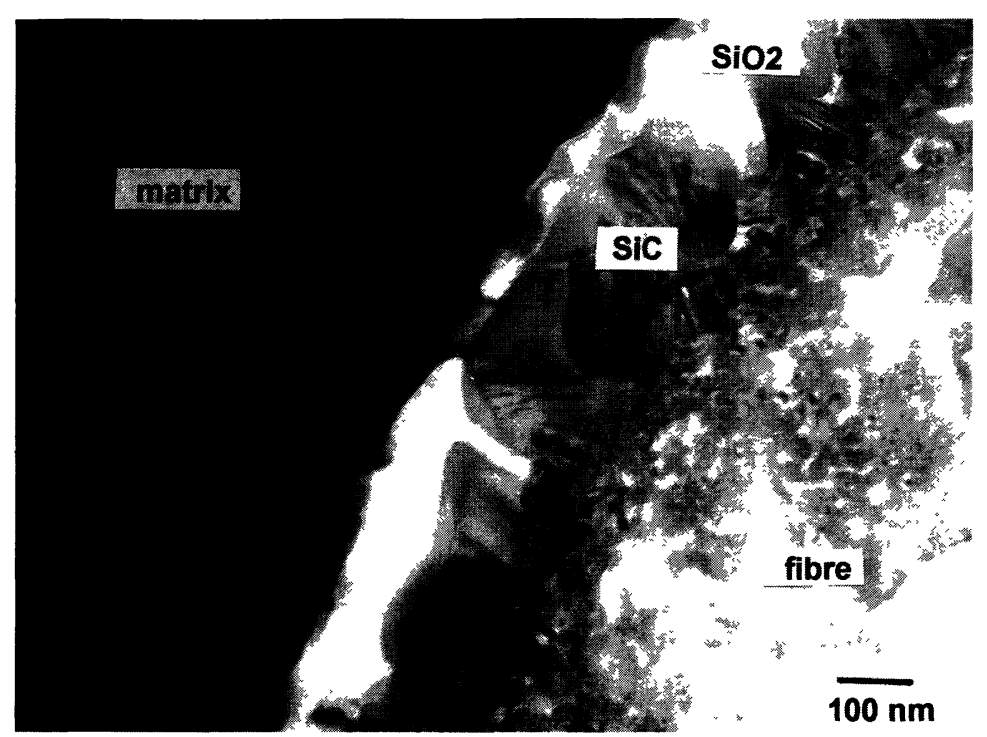

b)

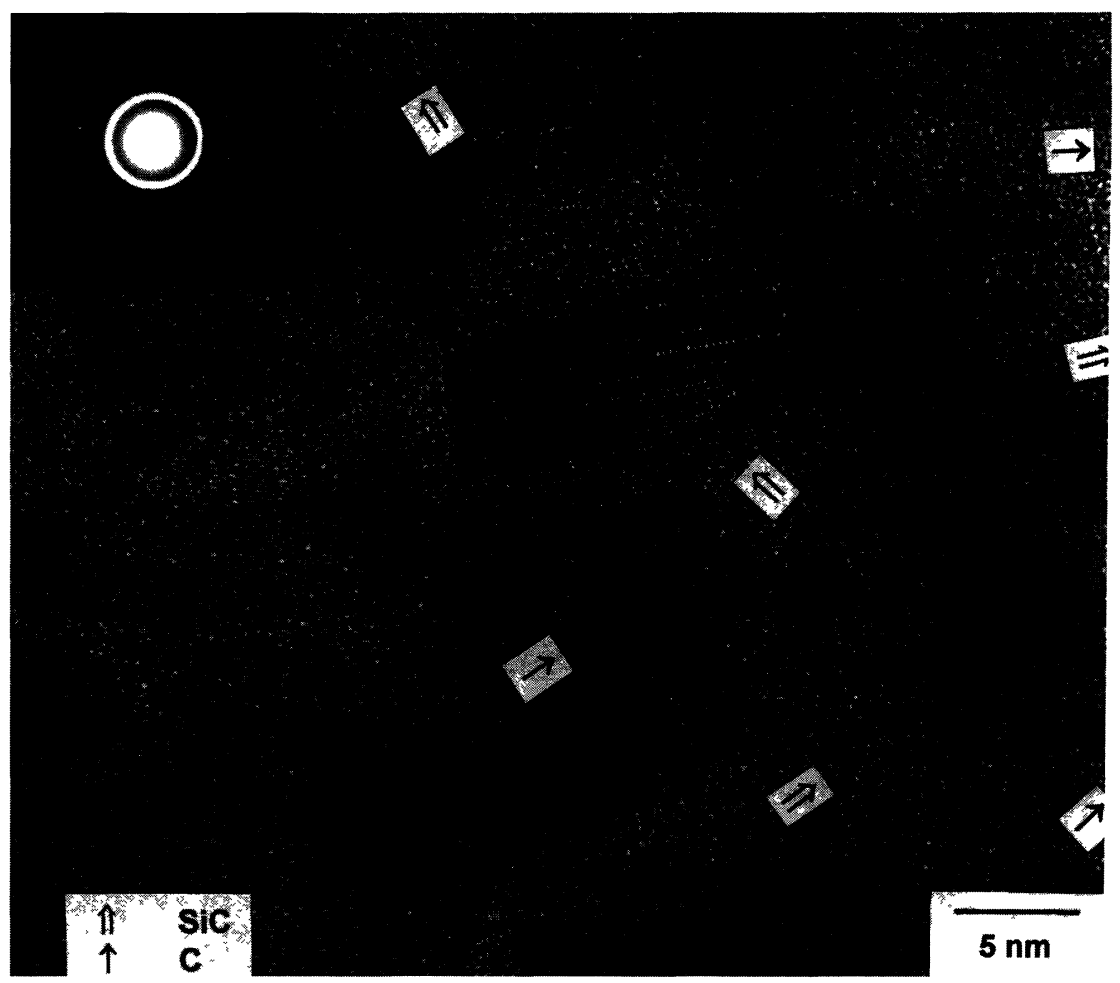

Fig. 3. - a) TEM bright field image and b) HREM image with corresponding diffraction pattern of the Nicalon fibre of a composite annealed at $1673 \mathrm{~K}$ in neutral atmosphere.

fibre core in an as-fabricated composite as a function of a) silicon peak intensity (Van Cappellen method), b) relative sample thickness $t / \lambda$ (obtained from PEELS), and c) thickness $t$ 


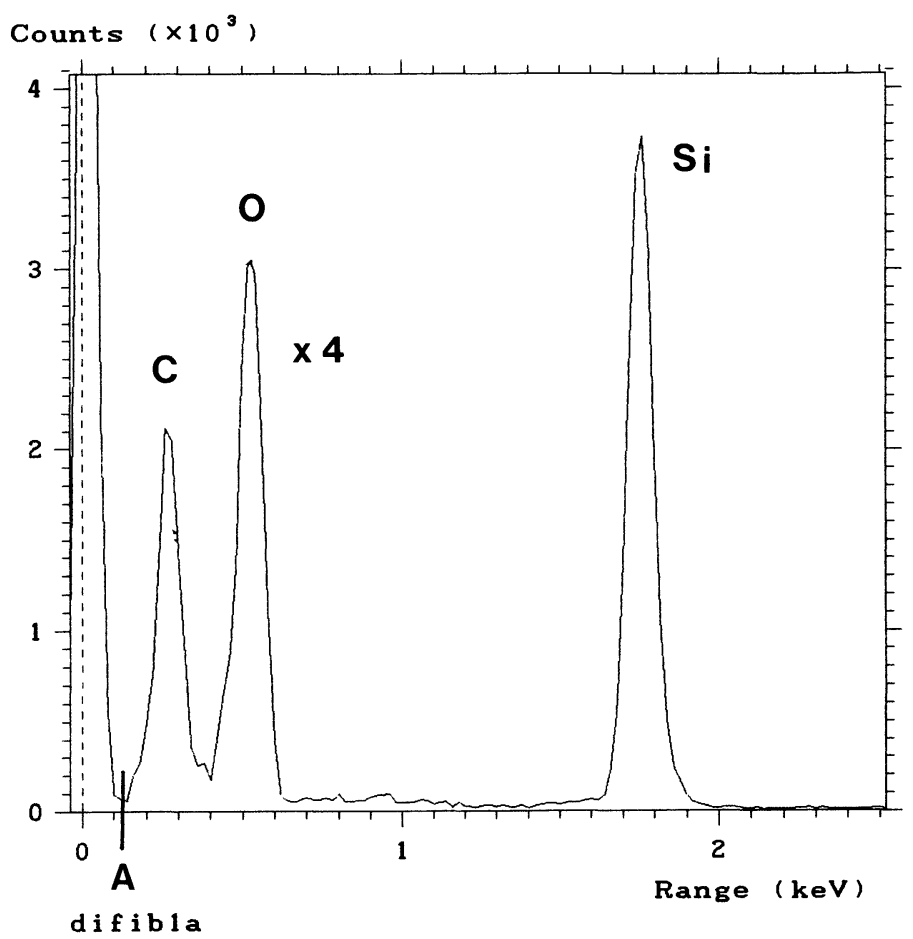

Fig. 4. - Typical EDX spectrum of the fibre core in the as-fabricated composite. The intensity is multiplied by a factor of 4 between 0 and $1.15 \mathrm{KeV}$.

(see Sect. 2.3.2). The importance of absorption correction is evident from Figure 6. Even for small thicknesses the intensity ratios vary greatly. The apparent carbon concentration corresponding to these curves dicreases from 25 to $10 \%$ for thicknesses from $30 \mathrm{~nm}$ to $600 \mathrm{~nm}$. For oxygen, these variations are less important, but still significant. In such cases, an exact determination of the sample thickness, or the corresponding ISi value must be made.

Curves a) and b) are in good agreement. This indicates that the two methods, a) "Van Cappellen" and b) "thickness measurement", are equivalent for deducing $k$ factors. The first method needs an extrapolation to zero thickness. Using linear regression, the following $k$ factor values were obtained from Figure 6: a) $k_{\mathrm{C} / \mathrm{Si}}=2.5 \pm 0.1$, b) $2.65 \pm 0.08$ and a) $k_{\mathrm{O} / \mathrm{Si}}=1.45 \pm 0.07$, b) $1.44 \pm 0.04$. These values were obtained by extrapolating to zero thickness by both methods. The standard deviation corresponds to the calculated linear regression.

However, the "thickness measurement" method presents several advantages:

- contamination layer built-up can be controlled in real time from the low loss region which indicates changes in sample thickness,

- extrapolation to zero thickness is not necessary. Extrapolation of the curves is not easy when deviation from linearity occurs at low thicknesses.

- beam current instabilities do not largely affect sample thickness estimation in EELS because of the short acquisition times. Current variations during the acquisition of several spectra, as needed for a Van Cappellen curve, may introduce a significant error in the reference element intensity. The larger scattering for a few points of oxygen analysis in silica in Figure 6a compared to Figure $6 \mathrm{~b}$ have to be attributed to such instability effects. 


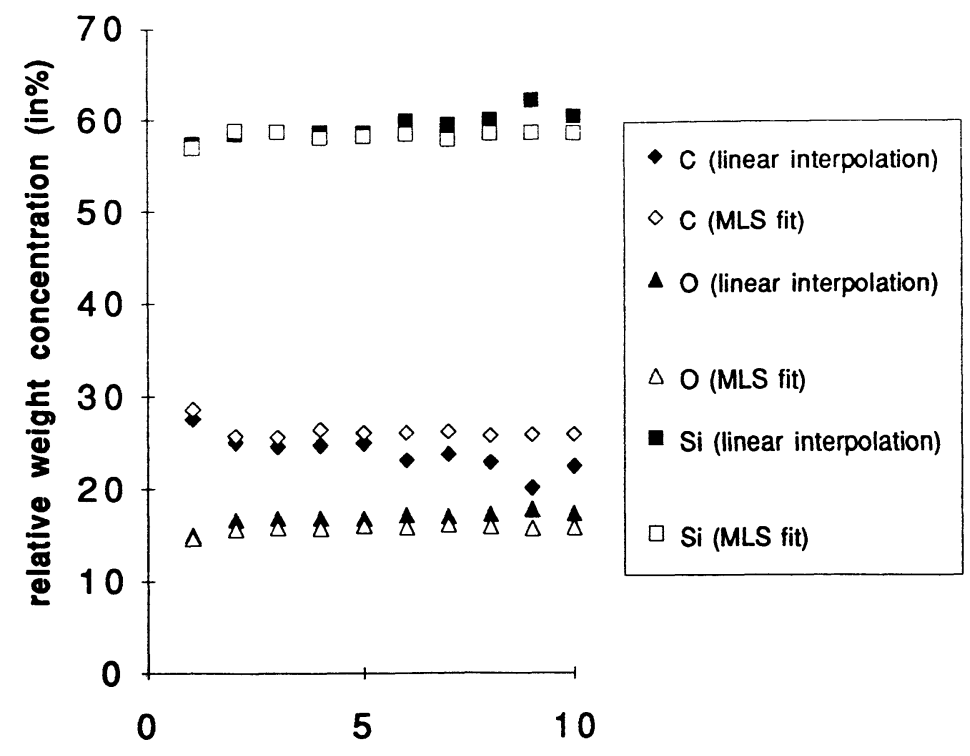

Analysed point number

Fig. 5. - Comparison of the relative weight concentrations of $\mathrm{C}, \mathrm{O}$ and $\mathrm{Si}$ obtained by EDXS in the fibre core of the as-fabricated composite by linear interpolation and MLS method (Van Cappellen method for absorption correction). Points 1 to 10 correspond to increasing thickness.

- only one analysis point is needed, if the mean free path is known and if the sample thickness lies in the range where classical absorption (Philibert-Tixier equation) applies.

3.2.3 Experimental Versus Theoretical Correction of Absorption Effects. - Figure 7 presents the carbon, oxygen and silicon concentrations after absorption correction. In this figure, results obtained with the Van Cappellen method are displayed in white characters, while those from the Philibert-Tixier equation and EELS sample thickness measurements appear in black. For better comparison, the Van Cappellen results are also presented as a function of sample thickness, obtained from simultaneously acquired EELS spectra. This demonstrates that the results for the two different absorption correction approaches are nearly identical. Constant composition $(<5 \%$ relative for carbon) is obtained for sample thicknesses between 35 and $500 \mathrm{~nm}$. The range corresponds to the quasi linear region in Figure 6. Experimental results in this thickness range support the Philibert-Tixier linear model. For larger sample thickness than $300 \mathrm{~nm}$, experimental points do not fit the linear regression and the linear absorption correction of Philibert-Tixier is no longer valid. For very thin foils $(<30 \mathrm{~nm})$, linear behaviour is again not followed, because significant variations in the chemical composition occur due to sample thinning.

From our results we concluded that the Philibert-Tixier equation can be used together with EELS sample thickness determination in a sample thickness range of $50-400 \mathrm{~nm}$. The best procedure is to apply the Van Cappellen method only for reference specimens. To avoid an eventual error in the $k$ factor determination by extrapolating to zero thickness and to perform analysis on inhomogenous complex materials, thickness measurements by EELS were systematically taken for each spectrum acquisition for standards and studied material.

The chemical compositions calculated from both absorption methods for the core and periphery regions of the fibre in as-fabricated and annealed composites are listed in Table III. These EDXS results were compared to EELS results (3.4) and discussed in term of material in section 4. 


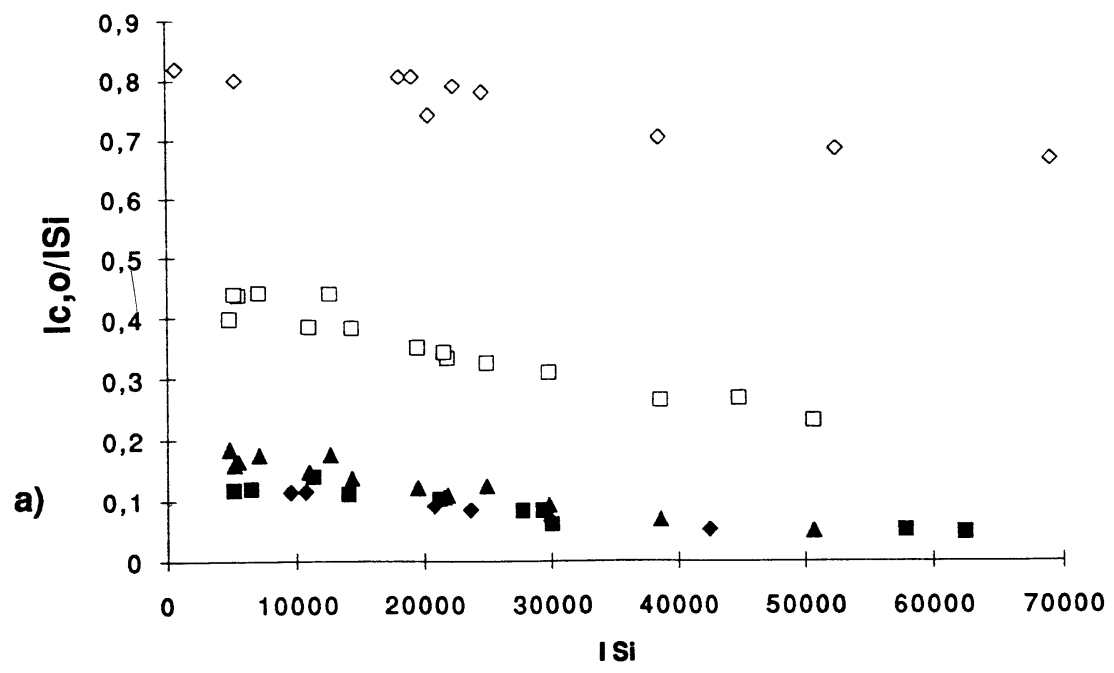

$\Delta$ IC/ISi fibre •IC/SiSiC ICASi SiC HIP $\square$ Io/Si fibre $\diamond$ Io/ISi SiO2 matrix

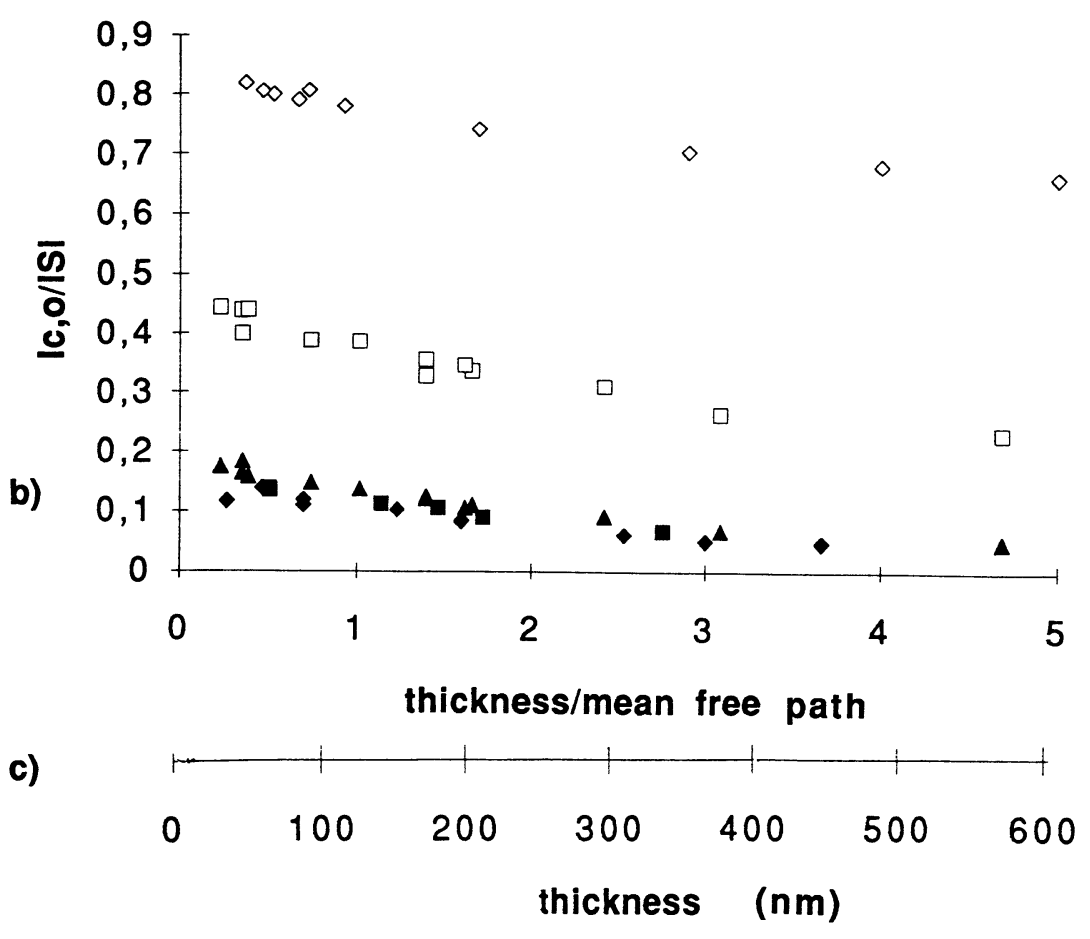

Fig. 6. - Carbon/silicon and oxygen/silicon EDX peak intensity ratios for $\mathrm{SiC}$ (HIP), $\mathrm{SiC}$ matrix, $\mathrm{SiO}_{2}$ and the as-received composite as a) function of the silicon intensity (Van Cappellen method), b) function of $t / \lambda$ obtained by simultaneously acquired PEELS and of thickness $t$ after estimation of the mean free path $\lambda$. The $I_{\mathrm{O} / \mathrm{Si}}$ ratio in the fibre is multiplied by a factor of 2 . 


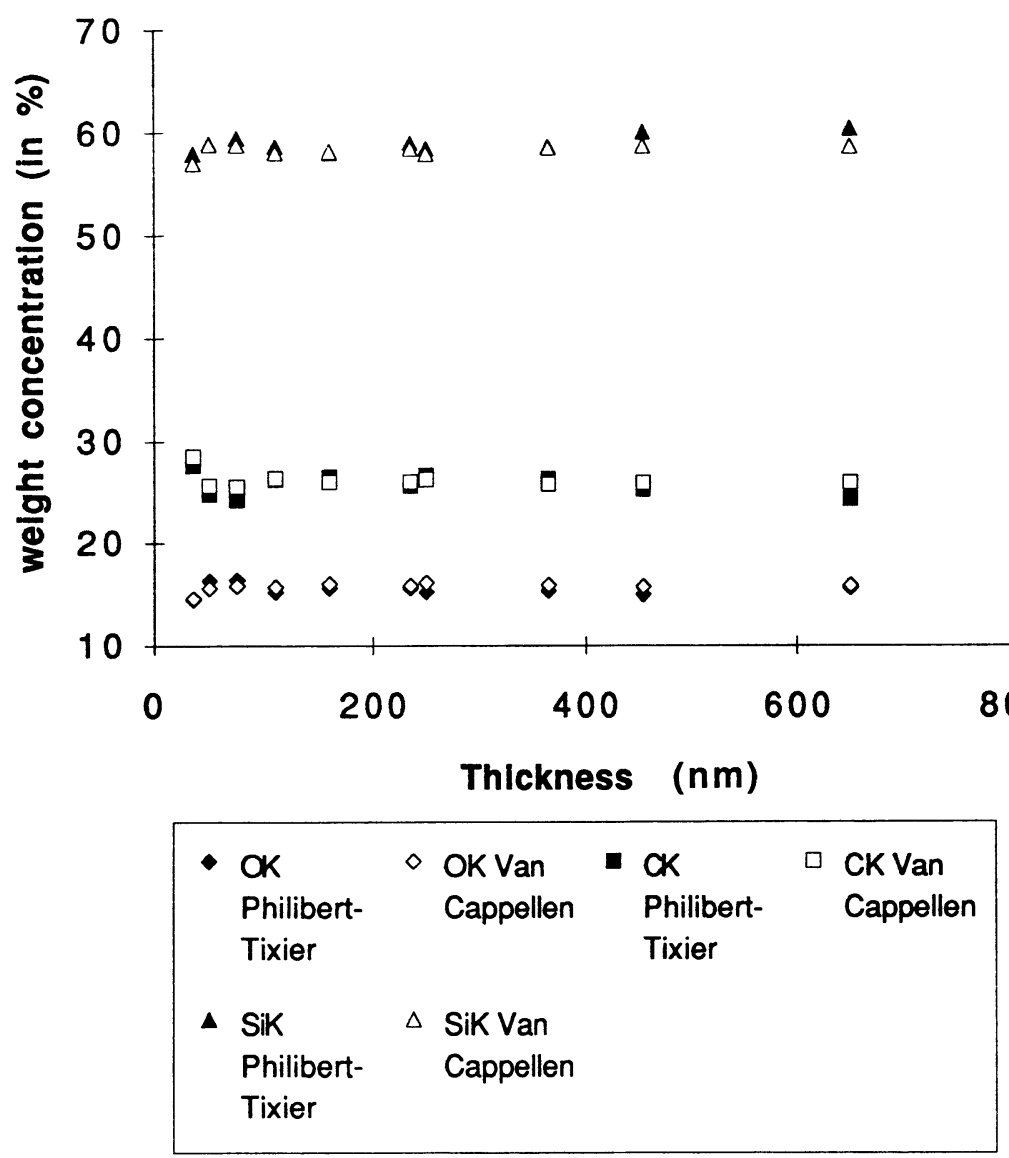

Fig. 7. - Evolution of the relative weight concentrations with thickness of $\mathrm{C}, \mathrm{O}$ and $\mathrm{Si}$ in the fibre core for the as-fabricated composite by EDXS, with absorption correction by Van Cappellen method and PhilibertTixier model.

3.2.4 Measurement Reproducibility and Accuracy. - Since high reproducibility is sought for the quantification of light elements, the $k$ factors of the reference standards must be acquired under exactly the same conditions of beam and detector response as those used to generate the experimental sample spectra. This objective can best be met when standard spectra are acquired on the same thin foil during each TEM session. In our case, we used the composite SiC matrix for the carbon standard and the silica product scale in the annealed composite for the oxygen standard. The $k_{\mathrm{C} / \mathrm{SI}}$ factors obtained for the composite matrix and HIP SiC are in good agreement (Fig. 6b).

To estimate the accuracy of the relative concentrations measured for the Nicalon fibre, an experimental error in $k$-factor determination, a statistical error in each peak intensity, and a normalisation to $100 \%$ must be applied to each element. The $k$ factor error corresponds to the standard deviation calculated during linear regression. The error introduced by EELS thickness measurements was small compared to that mentioned above. An error of $10 \%$ in the thickness introduces an error of only $2 \%$ for the carbon concentration. The $k$ factor error is $4 \%$ for carbon/silicon and oxygen/silicon for sample thicknesses between $50 \mathrm{~nm}$ and $500 \mathrm{~nm}$. The result for oxygen is not more precise than for carbon because of irradiation and local charge effects. Furthermore, 
Table III. - Comparison of EDXS and PEELS results in global composite fibre (in weight \%). Different methods of data treatment, various positions in the fibre, and the effect of different anneals are presented.

\begin{tabular}{|c|c|c|c|c|c|c|c|c|c|c|c|c|c|c|c|c|c|c|}
\hline \multirow{3}{*}{\begin{tabular}{|l} 
ANALYSIS METHOD $\rightarrow$ \\
TREATMENT $\downarrow$ \\
Element \\
\end{tabular}} & \multicolumn{9}{|c|}{ EDX } & \multicolumn{9}{|c|}{ EELS } \\
\hline & \multicolumn{3}{|c|}{$\begin{array}{l}\text { no absorption } \\
\text { correction }\end{array}$} & \multicolumn{3}{|c|}{ Van Cappellen } & \multicolumn{3}{|c|}{$\begin{array}{l}\text { Philibert-Tixier + } \\
\text { PEELS }\end{array}$} & \multicolumn{3}{|c|}{$\begin{array}{c}\text { SIGMAK(L) } \\
\text { plural scattering } \\
\text { neglicted }\end{array}$} & \multicolumn{3}{|c|}{$\begin{array}{c}\mathbf{k} \text { factor } \\
\text { method. } \\
\text { SiC+SiO2 } \\
\text { standards }\end{array}$} & \multicolumn{3}{|c|}{$\begin{array}{l}\text { k factor } \\
\text { method. } \\
\text { Fibre core } \\
\text { reference }\end{array}$} \\
\hline & C & $\mathbf{S i}$ & 0 & C & $\mathrm{Si}$ & 0 & C & Si & 0 & $\mathrm{C}$ & $\mathbf{S i}$ & 0 & $\mathbf{C}$ & $\mathrm{Si}$ & 0 & C & Si & o \\
\hline $\begin{array}{l}\begin{array}{l}\text { Fibre core } \\
\text { as-fabricated }\end{array} \quad \begin{array}{c}\text { (weight \%) } \\
\text { (atomic \%) }\end{array} \\
\end{array}$ & 19.3 & 65.8 & 14.9 & $\begin{array}{l}29.1 \\
45.6 \\
\end{array}$ & $\begin{array}{l}57.2 \\
38.3 \\
\end{array}$ & $\begin{array}{l}13.7 \\
16.1 \\
\end{array}$ & $\begin{array}{r}28.7 \\
45.2 \\
\end{array}$ & $\begin{array}{l}57.8 \\
38.3 \\
\end{array}$ & $\begin{array}{l}13.5 \\
15.9 \\
\end{array}$ & 19.6 & 63.6 & 16.8 & 33.3 & 55.2 & 11.5 & $\begin{array}{l}30.1 \\
46.9 \\
\end{array}$ & $\begin{array}{l}56.8 \\
37.8 \\
\end{array}$ & $\begin{array}{l}13.1 \\
15.3 \\
\end{array}$ \\
\hline standard deviation & 5.7 & 7.1 & 1.5 & 0.9 & 0.5 & 0.4 & 1.1 & 0.8 & 0.6 & 3.8 & 4.7 & 1.7 & 1.55 & 2.5 & 2.3 & 1.3 & 1.5 & 0.5 \\
\hline $\begin{array}{l}\text { Fibre periphery } \\
\text { as-fabricated } \\
\text { (average value) }\end{array}$ & $\mathbf{x}$ & $\mathbf{x}$ & $\mathbf{x}$ & $\mathbf{x}$ & $\mathbf{x}$ & $\mathbf{X}$ & $\begin{array}{r}32 \\
48.6 \\
\end{array}$ & $\begin{array}{c}53 \\
34.4\end{array}$ & $\begin{array}{l}15 \\
17\end{array}$ & $\mathbf{x}$ & $\mathbf{x}$ & $\mathbf{x}$ & 37.1 & 47.7 & 15.2 & $\begin{array}{l}35.8 \\
52.6 \\
\end{array}$ & $\begin{array}{c}49 \\
30.8\end{array}$ & $\begin{array}{l}15.1 \\
16.6\end{array}$ \\
\hline $\begin{array}{l}\text { Neutral atmosphere } \\
\text { Fibre core }\end{array}$ & $\mathbf{x}$ & $\mathbf{x}$ & $\mathbf{x}$ & $\mathbf{x}$ & $\mathbf{x}$ & $\mathbf{x}$ & $\begin{array}{c}30 \\
46.8\end{array}$ & $\begin{array}{l}57 \\
38\end{array}$ & $\begin{array}{c}13 \\
15.2\end{array}$ & $\mathbf{x}$ & $\mathbf{x}$ & $\mathbf{x}$ & 33.2 & 53 & 11.8 & \begin{tabular}{l|l|}
32.1 \\
48.9
\end{tabular} & \begin{tabular}{l|l|}
54.2 \\
35.3
\end{tabular} & $\begin{array}{l}13.7 \\
15.7\end{array}$ \\
\hline $\begin{array}{l}\text { Neutral atmosphere } \\
\text { Fibre periphery } \\
\text { (average value) }\end{array}$ & $\mathbf{x}$ & $\mathbf{x}$ & $\mathbf{x}$ & $\mathbf{x}$ & $\mathbf{x}$ & $\mathbf{X}$ & $\begin{array}{c}26 \\
42.3\end{array}$ & $\begin{array}{l}62.1 \\
43.2\end{array}$ & $\begin{array}{l}11.9 \\
14.5\end{array}$ & $\mathbf{X}$ & $\mathbf{x}$ & $\mathbf{x}$ & 63.9 & 24.8 & 11.3 & $\begin{array}{c}23 \\
38.5\end{array}$ & $\begin{array}{c}65 \\
46.5\end{array}$ & $\begin{array}{c}11.9 \\
15\end{array}$ \\
\hline $\begin{array}{l}\text { Oxidising atmosphere } \\
\text { Fibre core }\end{array}$ & $\mathbf{x}$ & $\mathbf{X}$ & $\mathbf{x}$ & $\mathbf{x}$ & $\mathbf{x}$ & $\mathbf{x}$ & $\begin{array}{l}27.5 \\
43.7\end{array}$ & $\begin{array}{l}58.7 \\
39.9\end{array}$ & $\begin{array}{l}13.8 \\
16.4\end{array}$ & $\mathbf{x}$ & $\mathbf{x}$ & $\mathbf{x}$ & $\mathbf{x}$ & $\mathbf{X}$ & $\mathbf{x}$ & $\mathbf{X}$ & $\mathbf{x}$ & $\mathbf{x}$ \\
\hline $\begin{array}{l}\text { Oxidising atmosphere } \\
\text { Fibre periphery } \\
\text { (average value) }\end{array}$ & $\mathbf{x}$ & $\mathbf{x}$ & $\mathbf{x}$ & $\mathbf{x}$ & $\mathbf{x}$ & $\mathbf{x}$ & $\begin{array}{c}24.3 \\
39\end{array}$ & $\begin{array}{r}58.3 \\
40\end{array}$ & $\begin{array}{r}17.4 \\
21 \\
\end{array}$ & $\mathbf{x}$ & $\mathbf{x}$ & $\mathbf{x}$ & 25.8 & 56.2 & 18.1 & $\begin{array}{l}24.2 \\
38.7 \\
\end{array}$ & $\begin{array}{l}57.3 \\
39.1 \\
\end{array}$ & $\begin{array}{l}18.5 \\
22.2 \\
\end{array}$ \\
\hline
\end{tabular}

a statistical error, which can be calculated from the characteristic peak area of each element of the composite, must be taken into account. This last error is supposed to follow a Gaussian law with a standard deviation, $\sigma$, proportional to the square root of the number of counts for each peak. At $3 \sigma$, the errors for carbon and oxygen are $6 \%$ and $2,5 \%$, respectively. This error for silicon can be neglected. These values are obtained for an acquisition time of $300 \mathrm{~s}$ and thickness below $300 \mathrm{~nm}$. The normalisation error on each concentration of each element is obtained from differential calculations. The global error in the composite fibre core is less than $10 \%$ for carbon $(29.0 \pm 2.8 \mathrm{wt} \%), 7 \%$ for oxygen $(13.5 .0 \pm 1 \mathrm{wt} \%)$ and $4 \%$ for carbon $(57.5 .0 \pm 2.3 \mathrm{wt} \%)$.

\subsection{ElEMENTAL COMPOSITION DETERMINATION BY EELS: HydRogeniC MODEL versus $k$} FACTOR METHOD. - Figure 8 shows a typical energy loss spectrum for a region without any visible silicon carbide crystals of the fibre core region of the as-fabricated composite. In the present work, only core edges and their associated fine structure are interpreted. Silicon, carbon and oxygen contents in the composite and in the different standards ( $\mathrm{SiC}$ of the composite matrix, $\mathrm{SiO}_{2}$ of the fibre product scale in heat-treated composites, HIP-SiC, and amorphous $\mathrm{SiO}_{2}$ ) were quantified by using their core edges, following the procedure described in section 2 . The edges of $\mathrm{Si}_{\mathrm{L}}$, $\mathrm{C}_{\mathrm{K}}$ and $\mathrm{O}_{\mathrm{K}}$ were sufficiently separated to treat the as-acquired spectra without any differentiation.

In the following we discuss how, for fixed collection and convergence angles, the choice of integration and fitting regions for background and ionization edges affected the quantification and how apparent concentrations changed with specimen thickness.

In a first step, the background was subtracted from the spectra in order to extract the characteristic inner shell signal. The background under the core edges was extrapolated by using a classical interval of $50 \mathrm{eV}$ with a $5 \mathrm{eV}$ background offset. The background offset is defined as energy between the high energy side of the interval and the edge threshold. This allowed to fit correctly a power law for $\mathrm{C}_{\mathrm{K}}$ and $\mathrm{O}_{\mathrm{K}}$ edges in $\mathrm{SiC}$ and $\mathrm{SiO}_{2}$ standards. Optimisation was more complicated for the $\mathrm{Si}_{\mathrm{L}}$ edge due to its location close to the low loss region and the important deviation from 


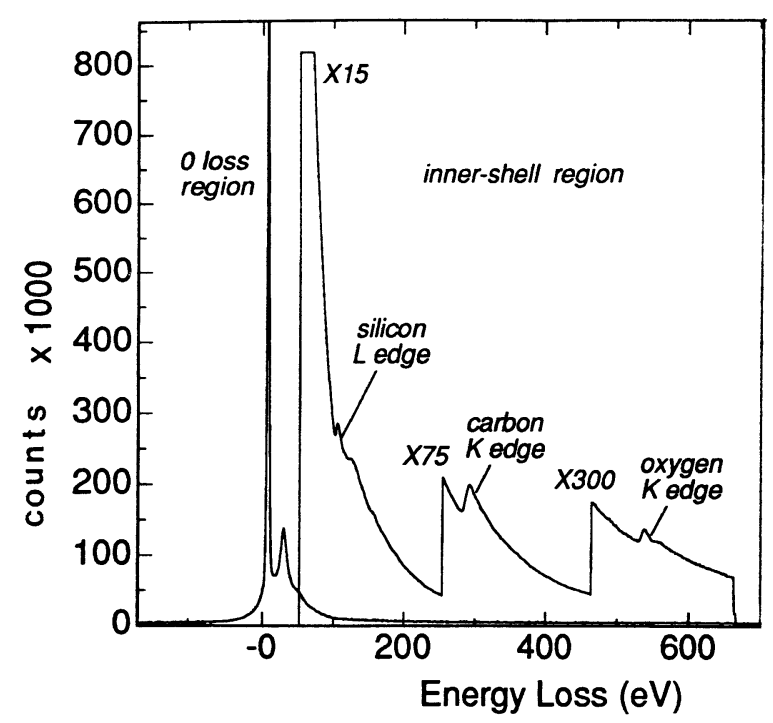

Fig. 8. - Typical energy loss spectra of the fibre core for the as-fabricated composite: low loss region and $\mathrm{Si}_{\mathrm{L}}, \mathrm{C}_{\mathrm{K}}$ and $\mathrm{O}_{\mathrm{K}}$ edges (energy dispersion $1 \mathrm{eV} / \mathrm{ch}$ and collection angle $10 \mathrm{mrad}$ ).

an ideal power law in that range. A small window of $20 \mathrm{eV}$ width was finally chosen as a compromise. For a broader interval, the silicon intensity was underestimated for all studied phases. For a narrower background interval, the background extrapolation under the core edge rapidly degraded with increasing distance from the energy edge threshold and the use of a large edge offset was impossible (the energy offset here is defined by the energy between the edge threshold and low energy side of the integration interval).

Cross sections were calculated by using the SIGMAK(L) program on $\mathrm{SiC}$ and $\mathrm{SiO}_{2}$ standards. The integration interval was optimised for the standarts and then applied to the composite fibre. Figure 9 shows the evolution of the apparent concentration ratios with the characteristics of the integration interval in the reference phases at a given relative specimen thickness $t / \lambda=0.4$ $(t=50 \mathrm{~nm}$ ), where multiple scattering remained negligible. (For smaller $t$ values, chemical composition changes occured due to sample preparation.) For an integration interval of $50 \mathrm{eV}$, the exact composition of $\mathrm{SiC}$ and $\mathrm{SiO}_{2}$ was obtained only for small edge offset values, which were $5 \mathrm{eV}$ and $20 \mathrm{eV}$, respectively. This fact may be explained by the presence of an important edge fine structure for $\mathrm{Si}_{\mathrm{L}}$, see Figure 10, and the limitation of the simple hydrogenic model, which considers no fine structure at all. For an offset of $30 \mathrm{eV}$ already a $10 \%$ error was found for SiC. For an integration interval of $100 \mathrm{eV}$ the offset values had to be changed in order to obtain the correct compositions of the reference standards (Fig. 9). For such large integration interval, the background could not be correctly extrapolated for $\mathrm{Si}_{\mathrm{L}}$ with a small background interval. An interval of $50 \mathrm{eV}$ was finally chosen for quantification purposes. However, the SIGMAK(L) program in general did not yield satisfactory results for the fibre. Therefore, preference was given to the experimental $k$ factor method.

For $k$ factor determination of $\mathrm{SiC}$ and $\mathrm{SiO}_{2}$ an integration interval was positionned with an edge offset of $35 \mathrm{eV}$ in order to minimize the influence of the fine structure (see Fig. 10). For the selected values of edge offset and integration interval, an effect of specimen thickness was expected. The $k$ factors were therefore determined as functions of sample thickness. The investigated thickness range was limited to $160 \mathrm{~nm}$ and $120 \mathrm{~nm}$ for $\mathrm{SiC}$ and $\mathrm{SiO}_{2}$ (Fig. 11a, b), 


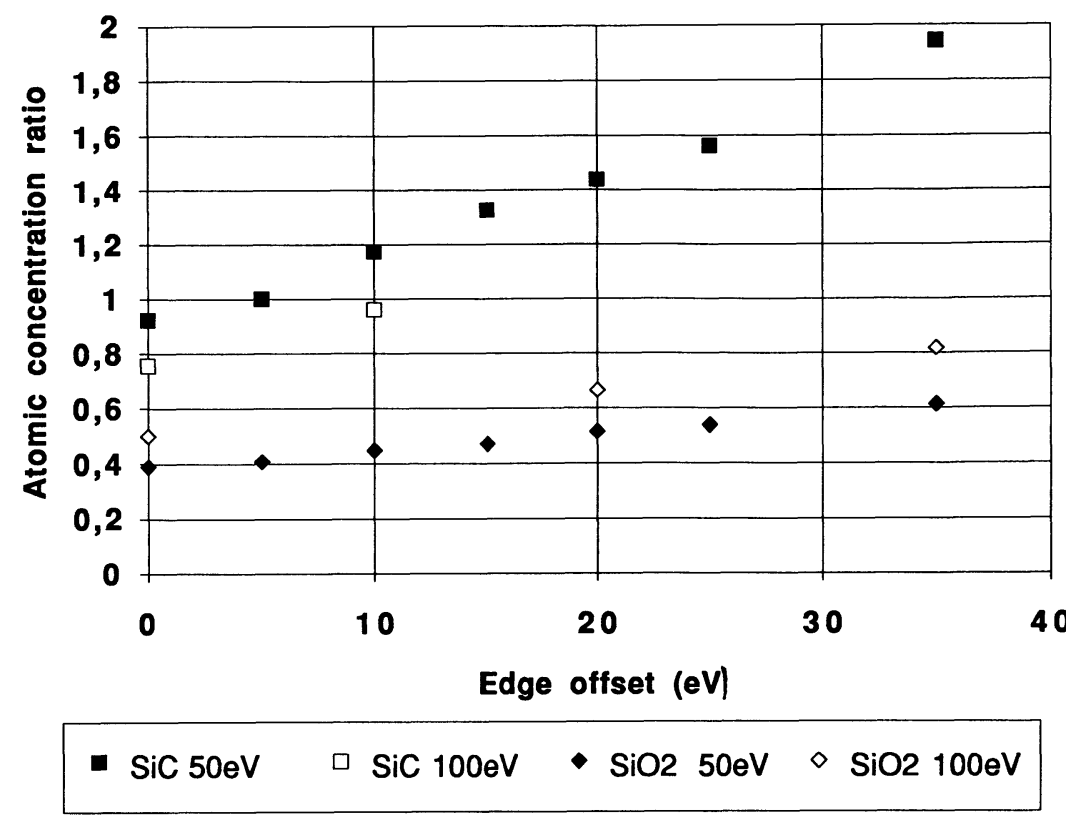

Fig. 9. - Evolution of the EELS apparent concentration ratio with position and width of the edge integration interval in $\mathrm{SiC}$ and $\mathrm{SiO}_{2}$ (specimen thickness $40 \mathrm{~nm}$, collection angle $10 \mathrm{mrad}$ ).

respectively. For larger thicknesses, plasmon effects and multiple scattering strongly decreased the $\mathrm{Si}_{\mathrm{L}}$ edge intensity in $\mathrm{SiO}_{2}$ and prevented any quantification. The intensity first increased with thickness and beam interaction volume and then at larger thickness decreased due to plural scattering (Fig. 11). This was observed for each edge. Changes in slope and intensity values in Figure 11 are related to both, fine structure and integration interval characteristics. In general, $k$ factors may evolve in a complex manner. For $\mathrm{SiC}$ and $\mathrm{SiO}_{2}$, with an edge offset of $35 \mathrm{eV}$, the linear approximation was only valid in a thickness range of $50 \mathrm{~nm}$ to $160 \mathrm{~nm}$ (Fig. 12) and $40 \mathrm{~nm}$ to $100 \mathrm{~nm}$ (Fig. 13), respectively. For smaller thicknesses, perturbations occured which were as in EDXS (see 3.2.4) explained by changes in chemical composition. The linear range was even more restricted for $\mathrm{SiO}_{2}$ at a smaller edge offset of $5 \mathrm{eV}$ (to sample thicknesses between $50 \mathrm{~nm}$ and $100 \mathrm{~nm}$ ). From the above results we selected the best experimental conditions to determine the $k$ factors and quantify the mixtures of the three elements: an integration interval of $50 \mathrm{eV}$ with an offset of $35 \mathrm{eV}$ and sample thicknesses between $50 \mathrm{~nm}$ and $100 \mathrm{~nm}$.

As a last step, we verified the validity of using the $k$ factors from the references $\mathrm{SiC}_{\text {and }} \mathrm{SiO}_{2}$ for the composite fibre. The fibre core in the as-received composite could also be used as a reference. Because of the small size and homogeneous distribution of the SiC crystals, the overall elemental composition was acquired for a beam size between $40 \mathrm{~nm}$ and $700 \mathrm{~nm}$. Figure 13 shows that the evolution of the $k_{\mathrm{O} / \mathrm{Si}}$ factor with thickness differs between the fibre and $\mathrm{SiO}_{2}$. The curve corresponding to the fibre in Figure 13 is divided by 5.5 to superpose the $\mathrm{SiO}_{2}$ curve at low thicknesses. The $k_{\mathrm{O} / \mathrm{Si}}$ factor in $\mathrm{SiO}_{2}$ decreased much more rapidly with thickness than $k_{\mathrm{O} / \mathrm{Si}}$ in the fibre. Reasons for this might be found in the use of a too small value of the mean free path in $\mathrm{SiO}_{2}$. It was only obtained by calculation [32] and not confirmed experimentally. The theoretical values of the mean free path were obtained for free electrons, a better approximation might be needed. The experimental verification of the theoretical mean free path for silicon carbide showed a $15 \%$ 

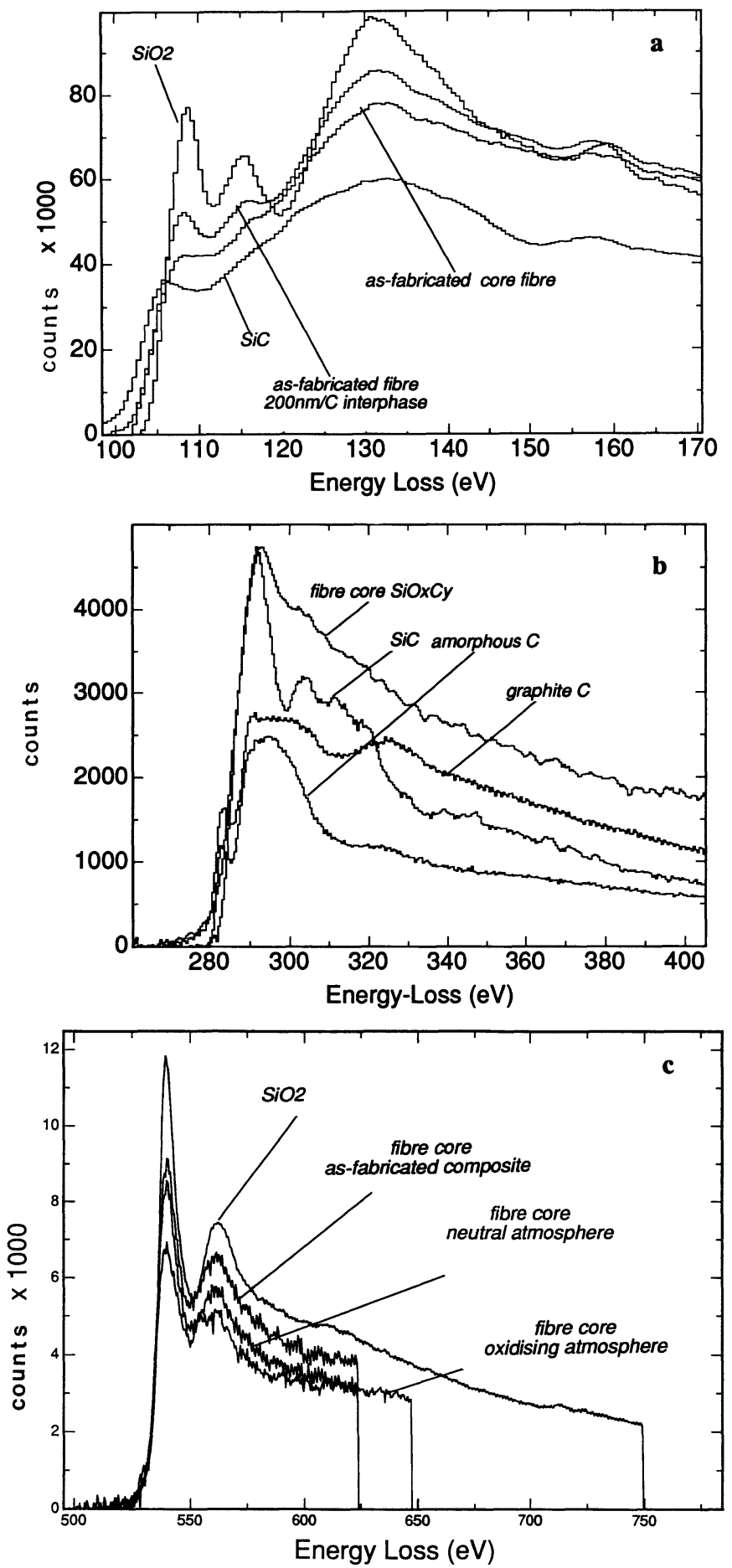

Fig. 10. - $\mathrm{Si}_{\mathrm{L}}$ a), $\mathrm{C}_{\mathrm{K}}$ b) and $\mathrm{O}_{\mathrm{K}}$ c) edge fine structures in the composite fibre, $\mathrm{SiC}, \mathrm{SiO}_{2}, \mathrm{C}$ graphite and amorphous phases. (collection angle $10 \mathrm{mrad}$, energy dispersion $0,5 \mathrm{eV} / \mathrm{ch}$, background was subtracted). 
(a)

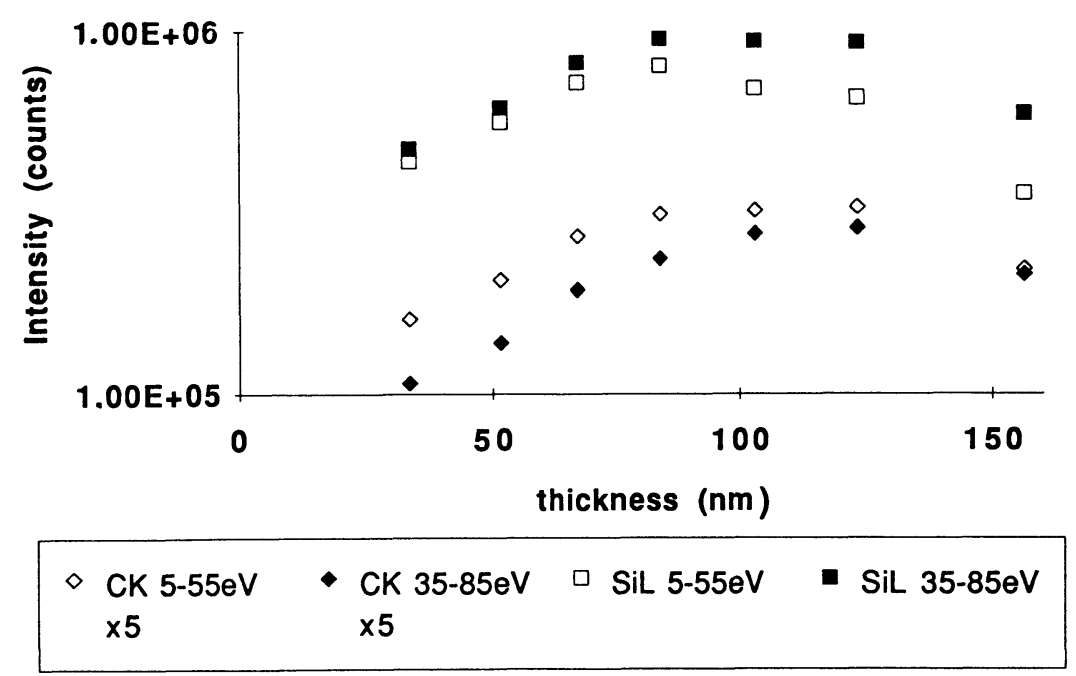

(b)

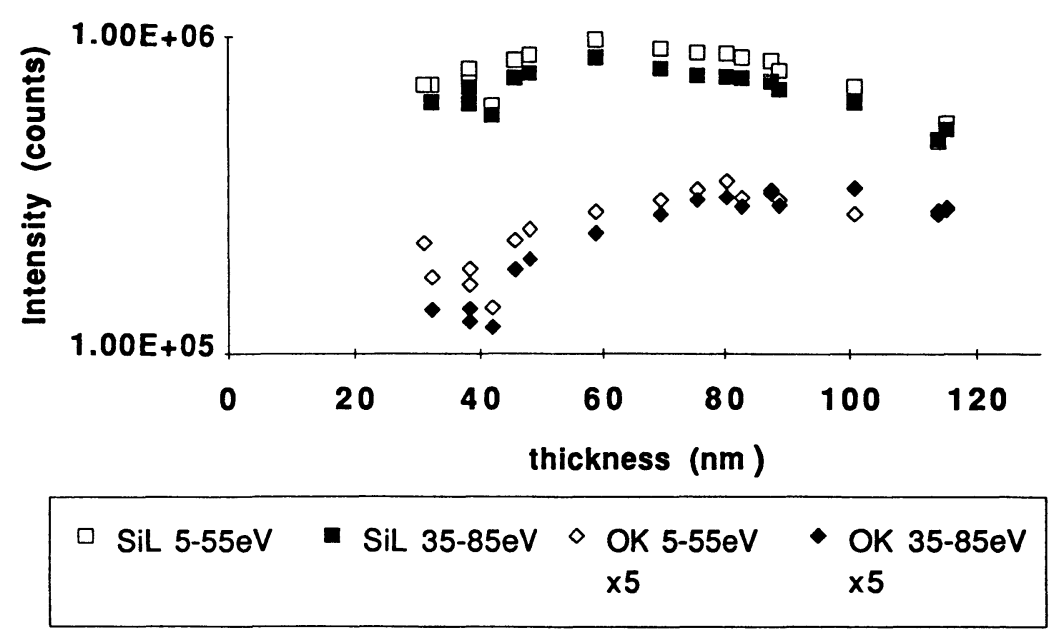

Fig. 11. - Effect of thickness on the EELS $\mathrm{Si}_{\mathrm{L}}, \mathrm{C}_{\mathrm{K}}$, and $\mathrm{O}_{\mathrm{K}}$ edge intensities in the reference standard a) $\mathrm{SiC} \mathrm{HIP}$ and $\mathrm{b}$ ) $\mathrm{SiO}_{2}$ for two edge integration intervals (collection angle $10 \mathrm{mrad}$, energy dispersion $1 \mathrm{eV}$ ). The $C_{K}$ and $O_{K}$ intensities were multiplied by a factor of 5 .

discrepancy. The extrapolation procedure was chosen in the same way for all curves and should therefore not be responsible. However, if the mean free paths of the electrons are different in 


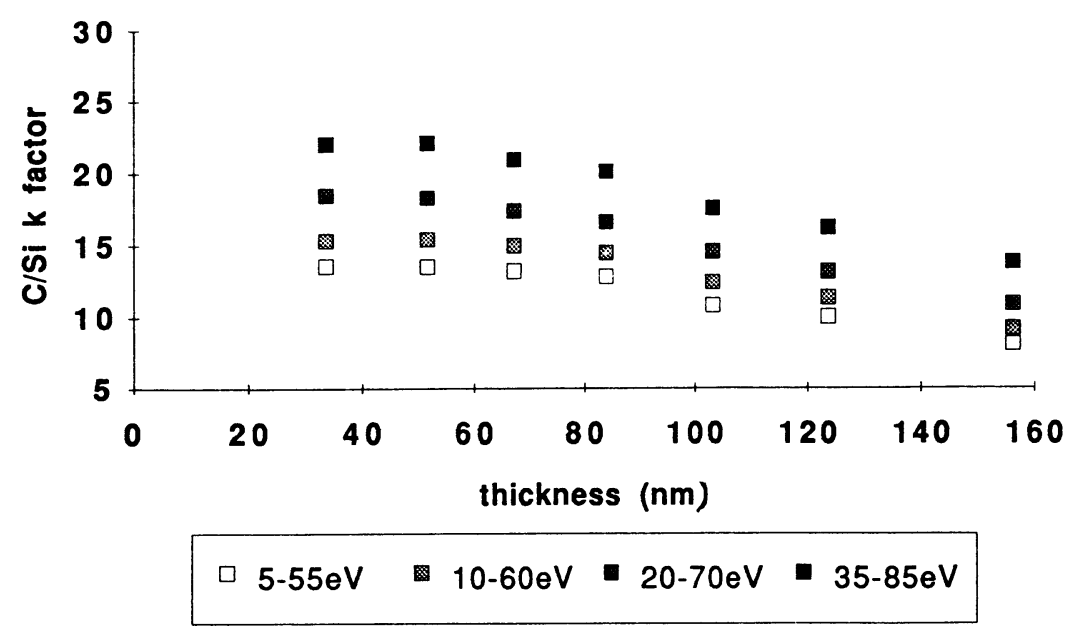

Fig. 12. - Evolution of the EELS $k$ factor $(\mathrm{C} / \mathrm{Si})$ with thickness in the reference standard $\mathrm{SiC}$ for different integration interval positions in the core edge (collection angle $10 \mathrm{mrad}$, energy dispersion $1 \mathrm{eV}$ ).

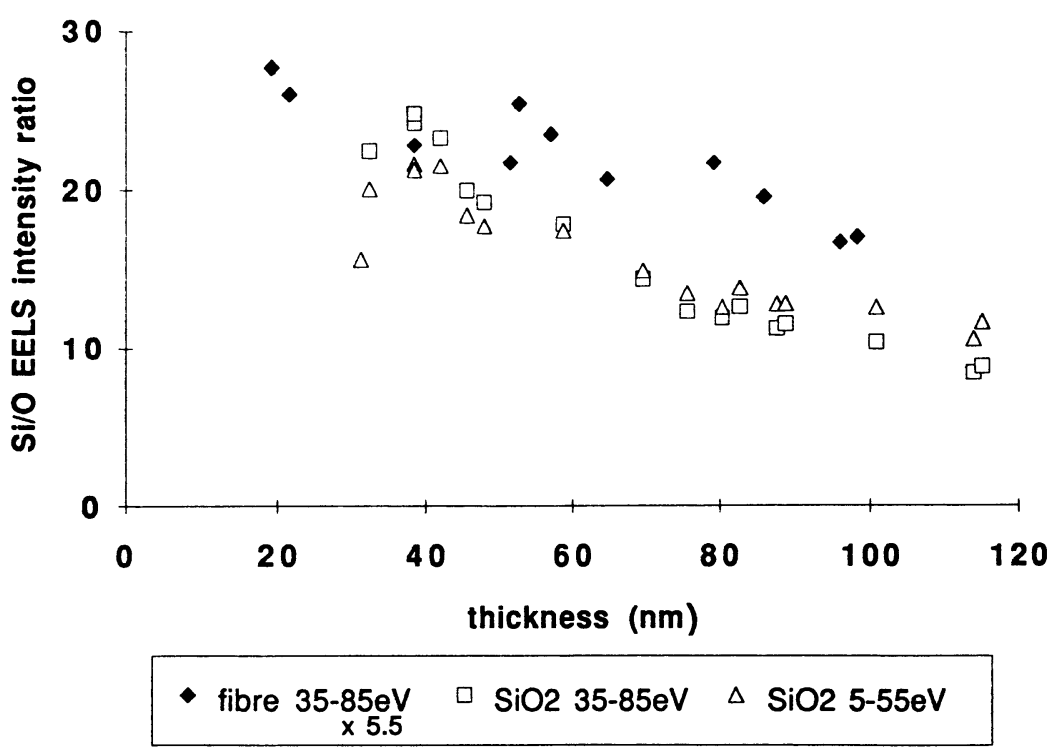

Fig. 13. - Evolution of the EELS $k$ factor $(\mathrm{O} / \mathrm{Si})$ with thickness in standard $\mathrm{SiO}_{2}$ and in the core fibre of the as-fabricated composite, for two edge offset values (collection angle $10 \mathrm{mrad}$, energy dispersion $1 \mathrm{eV}$ ).

silicon carbide and silica, an intermediate value should be expected in the fibre. From the curves in Figure 13, a correction of the $k_{\mathrm{Si} / \mathrm{O}}$ factor with thickness was derived. Its influence on the fibre core composition is shown in Figure 14. We concluded then that the fibre core region in the asfabricated composite served as a better standard for the fibre materials than $\mathrm{SiO}_{2}$ and used the $k_{\mathrm{O} / \mathrm{Si}}$ factor obtained in the core fibre for the EELS results presented in Table III.

For the $k_{\mathrm{C} / \mathrm{Si}}$ factor, no difference was observed between $\mathrm{SiC}$ and the fibre. 


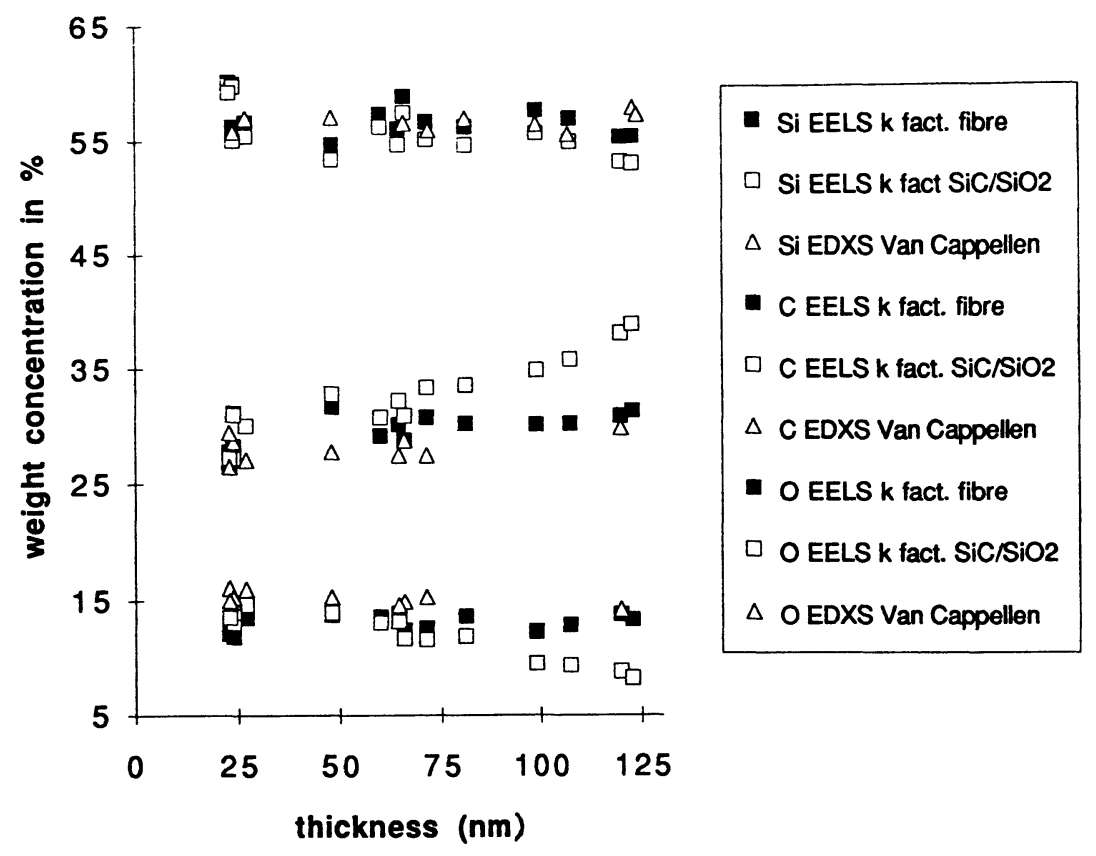

Fig. 14. - Comparison of the evolution of the relative weight concentration between EDXS and EELS with thickness of the fibre core (as-fabricated composite). Van Cappellen was used for EDXS. Two EELS $k_{\mathrm{O} / \mathrm{Si}}$ factors were used $\left(\mathrm{SiO}_{2}\right.$ and fibre core). (Collection angle $10 \mathrm{mrad}$, edge integration interval $50 \mathrm{eV}$ and edge offset $35 \mathrm{eV}$ ).

3.4 COMPARISON BETWEen PEELS AND EDXS QuANTITATIVE ANALYSIS. - EDXS and EELS results are summarized for the as-fabricated composite and materials annealed in air or under an argon flow in Table III. These results correspond to an average value obtained from a series of analysis in each condition. In the fibre core of the as-received composite, the phases were only a few nanometers in size and an average chemical composition was easily obtained using a $40 \mathrm{~nm}$ beam size. Under these conditions, the difference between the EDXS and EELS results was less than 5\%. In the annealed composite, the size of the $\mathrm{SiC}$ crystals was increased and either an average fibre composition using a large beam size $(>100 \mathrm{~nm})$ could be measured or one single phase could be selected with a beam size of $6 \mathrm{~nm}$. For large beam sizes (global analysis), satisfactory agreement within approximately $10 \%$ between the EDXS and EELS results was reached. For selected phase analysis with small beam size the quality of the analysis was often limited, because the $\mathrm{SiC}$ crystal size or the size of the amorphous regions did not strictly correspond to the analysed volume. However, single crystals of silicon carbide could be selected and yielded typical spectra of bulk silicon carbide. No differences related to the small size of the crystals could be detected. Using $6 \mathrm{~nm}$ beam size, local analysis of the amorphous silicon oxycarbide was not possible because it cannot be separated completly from the $\mathrm{SiC}$ phases. With smallest beam size and the $\mathrm{LaB}_{6}$ gun, the characteristic signal- background ratio is too low for quantitative analysis. The unic possibility for this quantification consists to deconvoluate the fine structure spectra mixed with $\mathrm{Si}_{\mathrm{C}}$ and $\mathrm{SiO}_{\mathrm{C}}$ phases and estimate their relative composition by a Multiple Least Square Fit. These results show that despite many obstacles, quantitative analysis of compounds containing light elements is possible for both techniques, EDXS and EELS, once the optimal conditions for spectra acquisition 
and treatment are selected. The EDXS and EELS results in Figure 14 show that multiple scattering in EELS and absorption in EDXS were correctly handled for restricted sample thickness. In EELS the $\mathrm{Si}_{\mathrm{L}}$ edge intensity drops rapidly with thickness, limiting the analysis to thicknesses up to $100 \mathrm{~nm}$, whereas EDXS analysis remains possible for thicknesses up to $700 \mathrm{~nm}$. In this work, we limited the application of EELS to thicknesses where the linear approximation for plural scattering can be used to correct the $k$ factor $(t<100 \mathrm{~nm})$. It is possible to slightly extend this correction to greater thicknesses by using a more sophisticated law for simulating the background signal.

It must be pointed out that the effect of multiple scattering on EELS quantification was more significant than the effect of X-ray absorption in EDXS for our fibre material, which had carbon contents of approximately $30 \%$. EELS quantification may give better results than EDXS for lower carbon concentrations, since EDXS would require longer acquisition times and thereby introduce the risk of sample contamination. EELS conserves its sensitivity.

Simultaneous EDXS and EELS acquisitions allow different techniques to be applied under the same operating conditions. This is especially interesting for light elements, where the signal intensity in EDXS is low (low fluorescence yield and low detector sensitivity) and quantification procedures normally used for heavy elements are no longer valid. However, in the past, simultaneous EELS- EDXS acquisition was rarely used for quantification analysis and was never conducted on these materials. Application of SIGMAK software and limitation to very small sample thickness are classical procedures of the past, but they are too restricted for ternary compounds and for complex materials. The procedures established in the present work, which take into account the near edge fine structures and multiple scattering, show that the $k$ factor determination is extremely important and that standards must be carefully selected for each material. The thickness domain used must be clearly precised.

\section{Conclusion}

4.1 EVAluATION OF THE EXPERIMENTAL TECHNIQUES. - The present results show that silicon, oxygen and carbon containing materials can be quantitatively analysed by EDXS and EELS within a precision less than $10 \%$ for carbon $(29.0 \pm 2.8 \mathrm{wt} \%), 7 \%(13.5 .0 \pm 1 \mathrm{wt} \%)$ and $4 \%(57.5 .0 \pm$ $2.3 \mathrm{wt} \%)$, as long as a certain number of precautions are taken:

- high stability of the beam current and fixed geometry

- no contamination (specimen cooling stage and limited beam radiation)

- no evolution in the detector response

- choice of optimum reference materials

For EDXS quantification, $k$ factors were experimentally determined using the Van Cappellen method, so that absorption and fluorescence effects could be excluded. Reference standards with compositions and phases as close as possible to the analysed material, were chosen and in-situ acquisition was preferred to using external standards.

We have shown, that for homogeneous materials, either the Van Cappellen method or the Philibert- Tixier absorption correction can be applied. The Philibert-Tixier correction requires the actual sample thickness, which can be determined from the low energy loss region of a simultaneously acquired EELS spectrum. The good agreement between both approaches confirms the validity of the linear Philibert-Tixier absorption correction in a large range of sample thicknesses for these materials (up to $t=400 \mathrm{~nm}$ ).

For inhomogeneous materials, the best technique is to use is EELS sample thickness determination and $k$ factors which are experimently corrected from absorption in standards.

Obstacles were encountered when quantifying the EEL spectra by using simulated spectra derived from a simplified hydrogenic model. Quantification was difficult due to the edge fine struc- 
ture and required that precautions be taken in choosing the background and integration intervals. For the silicon $L_{2,3}$ edge, problems became unresolvable, since fine structure features depended on the composition of the Si-O-C compound and the background power law was available only in small energy intervals.

For these reasons a "standard"-method was applied, where $k$ factors for selected standards were acquired as a function of sample thickness, integration intervals and spectrometer collection angle. Special integration interval sizes and positions were chosen in order to minimise the influence of the fine structure. The $k$ factor evolution with thickness was compared for reference phases and analysed material. Then, optimised $k$ factors were used for spectrum quantification.

The present work shows the complementarity of EELS and EDXS quantification of the chemical composition. Chemical analysis of 3D nanophases generally constitutes a difficult task for TEM, XPS, Auger, SIMS... In contrast to surface analysis techniques, high lateral resolution can be obtained in TEM, but depth resolution is limited by the sample thickness. However, these limits may be overcome by application of the different techniques available in TEM (i.e., simultaneous analysis of high resolution image, EDX and EEL spectra). An improved identification of the nanophases in the fibre can be obtained by using high resolution imaging together with information from the fine structure and the chemical shift of the EELS spectra, since for the Si-C-O compounds, the $\mathrm{Si}_{L_{2,3}}$ and $\mathrm{C}_{\mathrm{K}}$ absorption edges are highly sensitive to the chemical environment (Fig. 10). Such a chemical and structural analysis of the silicon oxycarbide phase in the fibre will be shown by the present authors in [33].

4.2 NEW RESULTS ON THE SiC-C-SiC COMPOSITE. - EDXS and EELS investigations allowed us to determine the global composition of the Nicalon fibre in the as-fabricated SiC-C-SiC composite $(29 \mathrm{wt} \% \mathrm{C}, 13.5 \mathrm{wt} \% \mathrm{O}, 57.5 \mathrm{wt} \% \mathrm{Si})$. These results are in agreement with those obtained by other techniques (Table 1). The different phases and their repartition were determined by HREM and electron diffraction. The fibre is composed of $2-3 \mathrm{~nm}$ size silicon carbide crystals and $1 \mathrm{~nm}$ size graphite units, which were surrounded by an amorphous oxycarbide phase. From HREM images the volume contribution of the different phases was estimated to be $50-60$ vol\% for silicon carbide and approximately 20 vol $\%$ for turbostratic carbon. Compared to the literature data, we observed a higher content of the amorphous oxycarbide phase.

In the outer periphery of the fibre in the as-fabricated composite the number of silicon carbide crystals and turbostratic carbon units decreased as compared to the core of the fibre, but the global composition showed only a slight increase in oxygen content $(+15 \%)$.

In the annealed composite the fibre underwent recrystallisation and changed its global chemical composition. After a $50 \mathrm{~h}$ anneal at $P_{\mathrm{O} 2}=10^{-6}$ atm and $1400^{\circ} \mathrm{C}$, the silicon carbide crystals reached sizes of $50 \mathrm{~nm}$. The carbon units maintained their original size. The large SiC crystals were again surrounded by the amorphous oxycarbide phase which, within experimental precision, preserved its chemical composition . EDXS and EELS analysis showed a small global decrease in the oxygen content $(-15 \%)$. Annealing in an oxidising atmosphere resulted in a smaller increase in the crystal size of the fibre: after $50 \mathrm{~h}, P_{\mathrm{O} 2}=0.21$ atm and $1400{ }^{\circ} \mathrm{C}$, silicon carbide crystals reached only $10 \mathrm{~nm}$, while the graphite units maintained their size. However, the fibre core composition did not change. At the periphery, the composition increased in oxygen $(25 \%)$ and the more oxidised zone was larger than in other atmospheres.

\section{Acknowledgements}

The authors want to thank the SEP for having provided the investigated composite. Furthermore, use of the microscope facilities was made possible by the Paris region "Reseau francilien". The 
work was partly conducted under the national project "Groupement Scientifique GS4c on thermomechanical properties of fibre reinforced composites", and received financial support from CNES, CNRS, DRET, MRT, Aerospatiale, SEP and SNECMA. A thin layer of SiC was elaborated by ultra high vacum evaporation and furnished by J. Dixmier, LPS-CNRS Meudon.

\section{References}

[1] Yajima S., Okamura K., Hayashi J. and Omori M., J. Am. Ceram. Soc. 59 (1976) 324-327.

[2] Hiroshi I., Haruo T. and Toshikatsu I., J. Mater. Sci. Lett. 6 (1987) 420-422.

[3] Yajima S., Hasegawa Y., Hayashi J. and Iimura M., J. Mater. Sci. 13 (1978) 2569-2576.

[4] Hasegawa Y., Iimura M. and Yajima S., J. Mater. Sci. 15 (1980) 720-728.

[5] Okamura K., Composites 18 (1987) 107-120.

[6] Fareed A.S., Fang P., Koczak M.J. and Ko F.M., Am. Cer. Soc. Bull. 66 (1987) 353-358.

[7] Lancin M., Anxionnaz F., Scuhmacher M., Dugne O. and Trebbia P., Mat. Res. Soc. Symp. Proc. 78 (1987) 231-244.

[8] Lipowitz J., Freeman H.A., Chen R.T. and Prack E.R., Adv. Cer. Mat. 2 (1987) 121-126.

[9] Filipuzzi L., Thèse Université Bordeaux I (1991).

[10] Vix C., Thèse Université de Haute Alsace (1991).

[11] Labrugere C., Guandte A. and Naslain R., Rapport GS4C (1992).

[12] Schreck P., Vix-Guterl C., Ehrburger P. and Lahaye J., J. Mater. Sci. 27 (1992) 4237-4246.

[13] Le Coustumer P., Monthioux M. and Oberlin A., J. Eur. Cer. Soc. 11 (1993) 95-103.

[14] Backhaus M., Mozdzierz N. and Imhoff D., J. Mat. Sci. (in press).

[15] Guigon M., Rev. Phys. Appl. 23 (1988) 229-238.

[16] Maniette Y. and Oberlin A., J. Mater. Sci. 24 (1989) 3361-3370.

[17] Monthioux M., Rapport GC4C (1991).

[18] Porte L. and Sartre A., J. Mater. Sci. 24 (1989) 271-275.

[19] Laffon C., Flank A.M., Lagarde P., Laridjani M., Hagege R., Orly P., Cotterey J., Dixmier J., Miquel J.L., Hommel H. and Legrand A.P., J. Mater. Sci. 24 (1989) 1503-1512.

[20] Mah T., Lecht N.L., McCullum D.E., Hoenigman J.R., Kim H.M., Katz A.P. and Lipsitt H.A., J. Mater. Sci. 19 (1984) 1191-1201.

[21] Bibbo G.S., Benson P.M.and Pantano C.G., J. Mater. Sci. 26 (1991) 5075-5080.

[22] Luthra K.L., J. Am. Ceram. Soc. 69 (1986) C231-C233.

[23] Johnson S.M., Brittain R.D., Lamoreaux R.H. and Rowcliffe D.J., Am. Ceram. Soc. 71 (1988) C132C135.

[24] Jaskowiak M.H. and Dicarlo J.A., J. Am. Ceram. Soc. 72 (1989) 192-197.

[25] Mozdzierz N., Thèse Université Paris Sud Orsay (1994).

[26] Labrugere C., Thèse Université Bordeaux I (1994).

[27] Warren R. and Andersson C.H., Composites 15 (1984) 101-111.

[28] Backhaus M., Mozdzierz N. and Eveno P., J. Phys. III (1993) 2189-2210.

[29] Van Cappellen E., Microsc. Microanal. Microst. 1 (1990) 1.

[30] Tixier R. and Philibert J., Proc. 5th. Intl. Cong. X-Ray Optics and Microanalysis, G. Möllenstedt and H. Gankler Eds. (Springer-Verlag, Berlin, 1969) 180.

[31] Cliff G. and Lorimer G. W., J. Micros. 103 (1975) 203.

[32] Egerton R. F., "Electron Energy Loss in the Eletron Microscope" (Plenum Press, New-York, 1986).

[33] D.Imhoff and M.Backhaus-Ricoult, MMM, in preparation. 